\title{
La vía califal entre Córdoba y Toledo. Pro- puesta metodológica de integración de la ruta a su entorno físico mediante SIG
}

\author{
The caliphal route between Cordoba and Toledo. Methodological proposal \\ of the integration of the path to its physical environment using GIS
}

Eneko López Martínez de Marigorta *

\begin{abstract}
RESUMEN
El presente trabajo analiza el trazado del camino que a mediados del siglo $X$ comunicaba Córdoba con Toledo. Para ello, se ha utilizado la herramienta SIG. Esta plataforma permite conocer el camino de mínimo coste entre dos localidades y lo hemos calculado entre las dos ciudades mencionadas, teniendo en cuenta la distancia, la orografía y la red hidrográfica. El artículo tiene la intención de mostrar las múltiples posibilidades de análisis que ofrece la herramienta SIG, así como de destacar el fácil acceso que posee la información georreferenciada. Estimamos que estas posibilidades aún no han sido ampliamente utilizadas por los arqueólogos e historiadores especializados en la Edad Media, a pesar de que nuestro estudio muestra que es factible aunar los datos procedentes de las fuentes textuales y materiales con los aportados por los modelos predictivos. De los tres objetivos propuestos, se han podido completar dos de ellos, por lo que se ofrece un apartado destinado a las fortalezas y debilidades que posee la metodología empleada.
\end{abstract}

Palabras clave: Córdoba, Toledo, califato omeya de Córdoba, camino, ruta óptima, SIG.

\section{CONTEXTO HISTÓRICO- ARQUEOLÓGICO}

A mediados del siglo $X$, al-Andalus era la región más desarrollada cultural y económicamente de todo el Mediterráneo occidental. Si atendemos a la política, la Península Ibérica musulmana estaba regida por el califato de Córdoba, cuyos gobernantes eran miembros de la dinastía omeya.

\begin{abstract}
This work analyzes the route of the road that in the middle of the I0th century connects Cordoba with Toledo. In order to achieve it, we have used the tool called GIS. This platform allows knowing the shortest path between two places and we have calculated it between the two aforementioned towns, valuing the distance, the orography and the hydrographic net. The article wants to show the many possibilities of analysis that the GIS offers, as well as to emphasize the easy access that the georeferenced information has. We consider that these possibilities have not been used at great length yet by the archaeologists and the historians specialized in the Middle Ages, even though our study shows that is feasible joining the data from the textual and material sources with those from the predictive models. We have achieved two of the three objectives that we initially had, so the work provides a section dedicated to the virtues and the weaknesses that the used methodology has.
\end{abstract}

Key words: Cordoba, Toledo, umayyad caliphate of Cordoba, road, shortest path, GIS.

Los musulmanes arribaron a Spania en el año 7lI, haciéndose con el control de la mayor parte del territorio peninsular. De este modo, la región pasó a formar parte del califato omeya de Damasco. Cuatro décadas más tarde, sin embargo, los gobernantes omeyas fueron desplazados por la dinastía abasí en el liderazgo del Islam. 'Abd al-Raḥmān I, uno de los descendientes de los califas derrocados, se alzó con el poder en al-Andalus en 756, creando

\footnotetext{
* Instituto de Historia. Centro de Ciencias Humanas y Sociales - Consejo Superior de Investigaciones Científicas (CCHS - CSIC)
} 
el emirato omeya de Córdoba. Esto supuso, de facto, la independencia administrativa de la Península Ibérica respecto al resto del Dār alIslām. Dicha autonomía se acentuó en el año 929, cuando 'Abd al-Raḥmān III se proclamó califa de Córdoba, asumiendo las prerrogativas religiosas junto a las políticas.

El territorio de al-Andalus se organizaba a través del centralismo administrativo ejercido desde la capital del califato: Córdoba. A mediados del siglo $X$, este núcleo urbano debía de contar con una población y unas dimensiones inmensas, pues los contemporáneos aseveraban que era como la mitad de Bagdad, justamente, la ciudad más grande del mundo y capital de la dinastía abasí (HAWQAL, 197I: p. 65). La división territorial andalusí se basaba en una veintena de kuwar o provincias, las cuales se situaban en el sector meridional de la Península Ibérica. Precisamente, esta zona era la que el califato controlaba de un modo más efectivo. Por otro lado, las regiones fronterizas se organizaban en torno a ciudades. Estas últimas circunscripciones territoriales mostraban una consolidación de la administración omeya menor que en las kuwar (MANZANO, 2006: pp. 425-433).

Ibn Hawqal fue un geógrafo musulmán que trabajó para el califato fatimí, es decir, la entidad política norteafricana que disputaba la hegemonía del Mediterráneo occidental a los omeyas. En calidad de espía, pero bajo la apariencia de ser un comerciante, viajó a lo largo de todo el Dār al-Islām. Entre otras regiones, recorrió alAndalus en 948. A comienzos de la década de 970, el viajero escribió una obra geográfica en la que, junto al mapa del mundo que entonces conocían, realizaba un análisis detallado de los distintos territorios que había visitado. Respecto al de la Península Ibérica musulmana, el autor agrupó los asentamientos de acuerdo con la zona de al-Andalus en la que se situaban. El geógrafo realizó una breve descripción de gran parte de estos emplazamientos, resaltando aspectos como la producción y las relaciones mercantiles. Finalmente, se analiza la red viaria andalusí, cuyo centro es Córdoba. Cinco son los caminos principales que parten de la capital, aquellos que se dirigen a Toledo, Valencia,
Almería, Sevilla y Badajoz. En ellos, Ibn Hawqal expuso la duración de los distintos tramos de la ruta, apuntando las localidades en las que se trasnochaba a lo largo del itinerario (HAWQAL, 1971: pp. 5-15 y 60-70).

Si atendemos a los medios de transporte utilizados a mediados del siglo $X$, una gran parte de los andalusíes viajaban en mulas procedentes, mayoritariamente, de Mallorca. De acuerdo con Ibn Hawqal, «las gentes ... no van a pie, a no ser, los que ejercen bajo oficios. Las mulas robustas son en efecto la especialidad del país» (HAWQAL, 197I: p. 67). En cuanto a la tipología de las vías califales que se dispusieron para el tránsito por al-Andalus, la documentación arqueológica que poseemos es más bien escasa. Destaca el tramo de un kilómetro del camino original del itinerario de Córdoba a Badajoz. «La calzada, de un ancho variable entre 4 y 7 $\mathrm{m}$, se presenta empedrada con esquisto de la sierra cuando no está tallada sobre la propia roca» (Resolución de 13 de mayo de 2002 [BOJA núm. 70, 15.6.2002]).

El presente trabajo tiene el objetivo de investigar la vía existente entre Córdoba y Toledo en el siglo $X$. La primera ciudad constituía la capital de al-Andalus, como ya hemos expuesto anteriormente. En ella se encontraba la residencia del califa y era la sede de la administración califal. Antes de la llegada de los musulmanes, el reino visigodo tenía su capital en Toledo. Tras la creación de al-Andalus, el asentamiento a orillas del río Tajo mantuvo su carácter urbano, siendo una de las cuatro ciudades más importantes del territorio andalusí, junto a Córdoba, Sevilla y Mérida (AL-BAKRT̄ 1982: pp. 24-32). La trascendencia de Toledo en la articulación del territorio andalusí también quedó plasmada en el nombre de una de las puertas que poseía la muralla de la medina cordobesa. Ciertamente, varias de las aberturas de las que disponía el muro exterior fueron denominadas de acuerdo con la ciudad en la que acababa dicho itinerario: la puerta nororiental se llamaba Bāb 'Abd al-Ŷabbār o Bāb Țulayțula, pues se trataba del inicio del camino que continuaba hasta Toledo (HERNÁNDEZ, 1959: pp. 7-8). En definitiva, se observa que, en el siglo 
X, el itinerario de Córdoba a Toledo era una de las principales vías de comunicación de la Península Ibérica.

No se trata de la primera vez que se va a estudiar el camino entre la capital andalusí y Toledo. En 1959, Félix Hernández Giménez escribió sobre dicho asunto en la revista AlAndalus. El autor del artículo era un arquitecto que, desde 1923 hasta su muerte en 1975 , dirigió las excavaciones llevadas a cabo en Madina al-Zahrā', esto es, la ciudad palatina erigida junto a Córdoba en la época califal. A la par de la dirección del conjunto arqueológico, el barcelonés realizó un estudio exhaustivo de las fuentes escritas, sobre todo en el ámbito de la geografía histórica de al-Andalus. Dentro de estos trabajos habría que enmarcar el artículo "El camino de Córdoba a Toledo en la época musulmana" (HERNÁNDEZ, 1959: pp. I-62), que analizaba el posible trazado que debió de tener el itinerario entre dichas dos ciudades en la época califal.

\section{REVISIÓN HISTORIOGRÁFICAY LA PRESENTE APORTACIÓN}

La historiografía del siglo XIX consideraba que la red viaria andalusí era una herencia directa de las rutas que seguían las calzadas romanas a lo largo de Hispania. Córdoba se situaba en el trazado de una de las calzadas más importantes de la Península lbérica romana, justamente, de la Vía Augusta. La ciudad a orillas del río Guadalquivir conectaba Cartagena con Sevilla. Mientras tanto, Toledo tenía una posición secundaria dentro de los itinerarios hispanos, pues ninguna de las vías principales transcurría por ella. Respecto al desplazamiento entre los dos asentamientos mencionados, no existía una comunicación directa entre ellos (TORRES, 1959: pp. 44I-444). El camino más corto de Córdoba a Toledo consistía en atravesar Mérida (ROLDÁN, 1975: Im. I). Por lo tanto, el itinerario directo entre la capital andalusí y la antigua capital visigoda debió de establecerse en una época posterior a la desaparición del Imperio Romano de Occidente, es decir, durante la dominación visigoda o musulmana.
El primer investigador que negó la correspondencia del camino califal de Córdoba a Toledo con una calzada romana fue Félix Hernández, en el ya mencionado artículo (HERNÁNDEZ, 1959: p. 44). Esta vía partía del Bāb Tulayțula cordobés, recorriendo numerosas localidades antes de llegar a la ciudad del Tajo, tales como Armillat, Hojalora, Fegabraen, el Puerto de Milagro y Pulgar (HERNÁNDEZ, 1959: pp. 6-34). El itinerario constituía prácticamente una línea recta, por lo que, a pesar de tratarse de un terreno bastante abrupto, parecía una aproximación al camino histórico más plausible que el de las calzadas romanas. Ciertamente, este trazado representa la distancia mínima entre las dos ciudades.

En aquellos años, surgió una propuesta alternativa a la del arquitecto barcelonés. Precisamente, Évariste Lévi-Provençal escribió los tomos IV y $V$ de la colección Historia de España, dirigida por Ramón Menéndez Pidal. Los dos volúmenes del francés, publicados en 1950 y 1957, se centraron en la Historia de al-Andalus hasta la desaparición del califato de Córdoba. En el quinto, el autor aseveraba que la ruta califal entre Córdoba y Toledo debía de coincidir con aquella descrita por Ibn Hawqal en su libro sobre geografía (LÉVI-PROVENÇAL, 1962: f. 55). El itinerario del viajero musulmán disponía de una mayor verosimilitud que el propuesto por Félix Hernández, debido a diversos motivos: por un lado, la obra geográfica del primero constituía una fuente directa de alguien que transitó la red viaria andalusí; en segundo lugar, Ibn Hawqal, en su labor como espía del califato fatimí, debía proporcionar la información más precisa posible de todo aquello relacionado con la entidad política beligerante, esto es, el califato de Córdoba; por último, el hecho de que no fuese andalusí limitaba bastante su capacidad para viajar por caminos poco transitados, por lo que es plausible pensar que utilizó las vías principales de al-Andalus.

Félix Hernández no hizo ninguna referencia al libro de Ibn Hawqal en su artículo. Posiblemente, sus conocimientos acerca de dicha obra fuesen escasos, ya que ésta solamente había sido editada en árabe, por M. J. de Goeje 
(HAWQAL, 1873) y J. H. Kramers (HAWQAL, 1938). La primera traducción al castellano de los capítulos referentes a al-Andalus fue la llevada a cabo por María José Romaní Suay en 1971 (HAWQAL, 197I: pp. II-15 y 60-70). Respecto al itinerario de Córdoba a Toledo, el geógrafo musulmán apuntaba que las localidades por las que se pasaba eran Caracuel, Calatrava, Malagón y Yébenes. Entre estos asentamientos únicamente habría una jornada de viaje, por lo que se trasnochaba cada día en uno de ellos. Excepto de Córdoba a Caracuel, pues eran necesarias cuatro jornadas para recorrerlo. En este último caso, también se pasaban las noches al resguardo, durmiendo en pueblos más pequeños que había en ese recorrido (vid. anexo I).

A través de la herramienta SIG, queremos analizar la viabilidad que potencialmente tienen los dos trayectos propuestos por Félix Hernández e Ibn Hawqal, para lo cual calcularemos el camino de mínimo coste entre Córdoba y Toledo, comparándolo con los dos anteriores. En segundo lugar, se tratará de matizar el itinerario descrito por el espía fatimí a mediados del siglo $X$, evaluando el camino de menor coste entre las localidades intermedias de la ruta. Igualmente, se intentará verificar que es posible la realización de los distintos tramos del trayecto en el número de días que lbn Hawqal apunta. En definitiva, el objetivo que nos hemos planteado consiste en precisar la vía existente entre las capitales andalusí y visigoda en época califal.

El estudio será una importante aportación para la Arqueología Medieval, ya que las futuras prospecciones que se realicen para localizar los distintos tramos del camino tendrán, como punto de partida, un modelo predictivo que facilitará la delimitación material de dicha ruta. Asimismo, los historiadores especializados en al-Andalus aprovecharán ampliamente los resultados de la presente investigación, sobre todo en los ámbitos de la Historia Económica y la Historia Militar. Ciertamente, la red viaria andalusí marcaba el recorrido que seguían los productos dentro del mercado interior. En cuanto al ejército, las campañas militares que se dirigían contra los reinos cristianos del Norte de la Península Ibérica se iniciaban con el reclutamiento de los soldados en Córdoba, para, a continuación, dirigirse hacia la mitad septentrional del territorio peninsular a través del itinerario a Toledo.

\section{JUSTIFICACIÓN DEL USO DE UN SIG}

Los SIG son «programas informáticos que permiten el almacenamiento y representación de datos digitalizados y referenciados por coordenadas geográficas, así como la manipulación y análisis de esta información para generar nuevos datos») (FAIRÉN, 2004: p. 30). En cuanto al nombre de la herramienta informática, éste responde a las siglas de Sistema de Información Geográfica, el cual, a su vez, proviene de la denominación inglesa Geographic Information System o GIS (RUBIO, GUTIÉRREZ, 1997: p. 94).

La utilización de la herramienta SIG en la Arqueología ha sido una constante desde los inicios de la década de 1990, si bien los primeros trabajos que hacían uso de la aplicación aparecieron en el decenio anterior (GARCÍA, 2005: p. 149). La importancia que en dicho periodo adquirió el SIG se debía, especialmente, a la consolidación de la Arqueología Espacial, centrada en el estudio de los datos arqueológicos en relación a la organización del territorio (ESPIAGO, BAENA, 1997: p. 42).

Nuestra investigación empleará la mencionada aplicación informática para integrar la ruta entre Córdoba y Toledo a su entorno físico. La posibilidad de evaluar el itinerario de menor coste entre dos puntos geográficos mediante la herramienta SIG fue ampliamente desarrollada por Jesús Bermúdez Sánchez en el estudio que llevó a cabo sobre el Calcolítico Final-Bronce Inicial en la campiña cordobesa. La obra, que constituyó la tesis doctoral de este arqueólogo, se tituló La aplicación de los Sistemas de Información Geográfica a la Arqueología (BERMÚDEZ 200 I). Tres de las investigaciones más recientes que han aprovechado el módulo de cálculo de caminos óptimos que posee el SIG han sido 
las llevadas a cabo por Sara Fairén Jiménez, Raúl López Romero y Roger Vilanou Vallès. La primera permitió conocer la articulación del territorio en el sector centro-meridional de la Comunidad Valenciana durante el Neolítico (FAIRÉN, 2004: pp. 25-40), a la vez que la segunda analizaba la ciudad-estado celtíbera de Segeda como cabecera del territorio circundante a ella (LÓPEZ, 2005: pp. 95-I I I). Por último, el tercer trabajo estudió el recorrido de la Vía Augusta a lo largo del Pirineo Oriental (VILANOU, MUÑOZ, PÉREZ, 20I0).

La predicción de un camino de mínimo coste se basa en evaluar los valores que tienen las celdas o píxeles de la capa ráster para, a continuación, unir dos puntos vectoriales atravesando el conjunto de celdas que supongan un menor valor acumulado (BURILLO et alii, 2008: p. 16). Precisamente, los datos georreferenciados se pueden presentar en dos formatos: ráster y vectorial. El primer formato plasma espacialmente el interior de los objetos a través de una red de celdas o píxeles de tamaño y forma regular. El formato vectorial, en cambio, define el perímetro de los objetos (GARCÍA, 2005: pp. 152-153). Si atendemos al tipo de modelo de cálculo que utilizaremos para obtener la ruta óptima entre Córdoba y Toledo, se trata del modelo anisotrópico, es decir, aquel en el que «el valor del coste de las celdas de una superficie de fricción no es único porque depende de la dirección que se tome al cruzar la celda» (VILANOU, MUÑOZ, PÉREZ, 2010). La razón para optar por este modelo se debe a que tomaremos en cuenta la pendiente, ya que no supone el mismo coste su ascenso que su descenso.

El procedimiento para el cálculo de un itinerario de menor coste comienza con la obtención de las curvas de nivel o isolíneas. Gracias a ellas, se puede elaborar un MDT - Modelo Digital del Terreno representado mediante el modelo TIN o Triangulated Irregular Network, esto es, una capa vectorial creada en base a la triangulación de Delaunay (LÓPEZ, 2005: p. 100). Acto seguido, es necesario transformar la malla vectorial en un MDT de tipo ráster. En tercer lugar, vamos a crear una capa ráster que se denomina superficie de fricción. Cada celda o píxel de esta malla posee el valor que supone recorrerla (VILANOU, MUÑOZ, PÉREZ, 20 I0). A la hora de evaluar sus costes, se deben tener en cuenta diversos factores. Entre otros, destacan la orografía, la red hidrográfica y la vegetación o los usos del suelo. Todos ellos son factores naturales, a los que habría que unir los culturales, caso de los caminos y los puentes (LÓPEZ, 2005: p. 99). El presente trabajo tomará en cuenta la orografía y la red hidrográfica, pero no la vegetación, ya que las fuentes materiales exponen que las principales vías del periodo califal estaban empedradas. Por lo tanto, la influencia de los tipos de suelo sobre el coste de atravesar un trazado concreto sería mínima. En cuanto a los puentes, carecemos de fuentes que informen sobre los puentes situados en la vía de Córdoba a Toledo, por lo que el modelo predictivo cruzará los ríos en base a su longitud.

La superficie de fricción posibilita elaborar la superficie de coste de recorrido. Cada uno de los píxeles de esta última capa ráster posee el valor acumulado de todas las celdas que se han atravesado hasta llegar a ésta (CONOLLY, LAKE, 2009: p. 28I). Dicho coste dependerá de la distancia y la dirección desde el punto de origen. Finalmente, el camino de mínimo coste se obtiene estableciendo los puntos vectoriales de origen y destino (BERMÚDEZ, 2004: p. 414), creándose una polilínea vectorial, es decir, una «secuencia ordenada de puntos relacionados mediante segmentos»)(ESPIAGO, BAENA, 1997: p. 19).

El procedimiento desarrollado hasta ahora ofrecerá una solución a los dos primeros problemas planteados: podremos integrar la ruta entre Córdoba y Toledo a su entorno físico, además de que evaluaremos el camino de mínimo coste entre las localidades intermedias del itinerario descrito por Ibn Hawqal. Estas dos rutas las compararemos con el itinerario propuesto por Félix Hernández. Pese a todo, el tercer problema, aquel que trata de verificar la realización de los distintos tramos de la vía del geógrafo musulmán en el plazo por él apuntado, no es posible solucionarlo con el procedimiento anterior. Para su resolución, es 
necesario calcular la ruta óptima, aquella que ofrece unos resultados absolutos '. Dentro de las distintas fórmulas que se utilizan para el cálculo de la ruta óptima, César Parcero Oubiña empleó una que previamente había sido teorizada por A. Díez:

$$
E=p / 10
$$

donde $\mathrm{E}$ es el esfuerzo y $\mathrm{p}$ la pendiente del terreno expresada en porcentaje (PARCERO, 2002: p. 66).

Por otro lado, el equipo de investigación dirigido por Marisa Ruiz-Gálvez Priego creó la siguiente fórmula:

$$
f=(1 / / 2) \times p+1
$$

donde $f$ es la fricción y $\mathrm{p}$ la pendiente en porcentaje (RUIZ-GÁLVEZ et alii, 2002: p. 270).

La ruta óptima obtenida mediante las fórmulas anteriores, sin embargo, no informa sobre el coste, valorado en tiempo, entre dos puntos georreferenciados. Por ello, consideramos otras funciones, caso de la desarrollada por Antonio Uriarte González:

$$
T=0,0277 R P+0,6115 R
$$

donde $T$ es el coste en segundos, $p$ la pendiente en porcentaje y $\mathrm{R}$ la resolución espacial en metros de la capa ráster (URIARTE, 2005: pp. 6|3-614).

Finalmente, hemos estimado que la función más adecuada para la presente investigación es el algoritmo de movilidad de Gorenflo y Gale:

$$
v=6 \mathrm{e}^{-3,5|s+0,05|}
$$

donde $v$ es la velocidad de movimiento en $\mathrm{km} / \mathrm{h}$ y $\mathrm{s}$ la pendiente en grados (CONOLLY, LAKE, 2009: pp. 286-288).

Dicha función fue creada para la predicción de rutas recorridas sobre caminos a pie. En el caso de que proyectásemos obtener la velocidad a pie fuera de caminos, habría que multiplicar el resultado por 3/5, mientras que para calcular el movimiento a caballo se multiplicaría por 5/4 (VILANOU, MUÑOZ, PÉREZ, 20I0). Respecto a los medios de transporte habituales en al-Andalus a mediados del siglo $X$, destacaban la mula y el desplazamiento a pie, como ya hemos explicado anteriormente. Por ello, usaremos el algoritmo de Gorenflo y Gale en dos de sus formas: primero, considerando que el trayecto se realiza sobre un camino y a pie; $y$, en segundo lugar, estimando que el itinerario se recorre a caballo.

\section{DISPONIBILIDAD DE LA INFOR- MACIÓN}

La mayor parte de las capas de información necesarias para desarrollar la presente investigación han sido facilitadas a través de Internet, pues en la red existe una considerable cantidad de servidores que las ofrecen. Primero, debíamos disponer de las curvas de nivel. No obstante, nos ha sido mucho más accesible el MDT en formato ráster del sector Suroriental de la Península Ibérica. Se trata del Modelo Digital del Terreno con resolución 90×90m obtenido por la Shuttle Radar Topography Mission o SRTM (VILANOU, MUÑOZ, PÉREZ, 20 I0). Dicha misión fue impulsada conjuntamente por la National Geospatial-Intelligence Agency - NGA y la National Aeronautics and Space Administration o NASA, esto es, las agencias estadounidenses de la información geoespacial y de los programas espaciales, respectivamente. El servidor que nos ha proporcionado el MDT de la SRTM es la versión 4 del Consorcio para la Información Espacial o CSI del Grupo Consultivo sobre Investigación Agrícola Internacional o CGIAR. Para la descarga de la capa, hemos accedido a la página web del CGIAR-CSI, http://srtm.csi.cgiar.org/. Dentro de ella, pinchamos en SRTM Data Search and Download. Nos aparece un mapamundi dividido en cuadrículas regulares, de las cuales seleccionaremos aquella que corresponde con

\footnotetext{
I Agradezco profundamente a los investigadores Brais X. Currás Refojos y Antonio Uriarte González las aclaraciones que me realizaron acerca de la metodología a seguir en el cálculo de la ruta óptima.
} 
la zona Suroriental de la Península Ibérica. A continuación, hacemos click en Click here to Begin Search (vid. fig. I). Por último, es necesario escoger Data Download (FTP). De este modo, hemos adquirido la capa de tipo ráster "srtm_36_05.tif".

La capa de información acerca de la red hidrográfica ha sido localizada en la página web del programa DIVA-GIS, http://www.diva-gis. org/. Una vez dentro, debemos pinchar en free spatial data (vid. fig. 2). Acto seguido, elegimos country level data. Finalmente, optaremos por Spain a la hora de definir el país e Inland water para concretar la temática de la capa que queremos descargar. Las dos opciones seleccionadas se confirman haciendo click en OK. Las descargas son dos capas vectoriales: "ESP_water_lines_dcw.shp" contiene los ríos de España, mientras que "ESP_water_areas_dcw. shp" guarda los embalses y lagos españoles.

El cálculo del camino de mínimo coste de Córdoba a Toledo requiere la creación de dos puntos vectoriales, "Córdoba.shp" y "Toledo.shp", que serán utilizados como origen y destino del modelo predictivo. La georreferenciación de los puntos se ha conseguido a través de la localización de las dos ciudades en Google Earth 5.1 y atribuyéndoles las coordenadas en la proyección Universal Transversal de Mercator o UTM que allí aparecen. De cara a la representación de la ruta óptima, hemos elaborado una capa vectorial en la que aparecen los dos puntos, denominada "Córdoba_y_Toledo.shp". A la hora de calcular el camino de menor coste entre las localidades intermedias del itinerario expuesto por Ibn Hawqal, requerimos la existencia de otros cuatro puntos vectoriales, que se llaman "Caracuel.shp", "Calatrava.shp", "Malagón.shp” y "Yébenes.shp". Conocemos el paso por estos asentamientos debido a la traducción al castellano del libro del geógrafo musulmán (vid. anexo I). Los cuatro puntos también serán georreferenciados mediante el uso de Google Earth 5.I. La representación del trazado de coste óptimo acumulado de la vía descrita por Ibn Hawqal contará con una malla vectorial en el que se incluyan los seis puntos de la ruta georreferenciados. Su nombre es "Localidades_de_la_ruta_de_Córdoba_a_Toledo.shp".

La comparación de la ruta propuesta por Félix Hernández y los modelos predictivos obtenidos a través de la herramienta SIG es posible gracias a la georreferenciación del mapa del artículo del primero (HERNÁNDEZ, 1959: pp. 32-33). Para ello, transformamos dicho mapa en una capa en formato ráster denominada "Camino de Félix Hernández.jpg" y unimos los puntos en común que tiene con la malla Localidades_de_la_ruta_de_Córdoba_a_Toledo.shp.

Para localizar la capa de información relativa a los municipios de España, hemos acudido a la página web del Instituto Geográfico Nacional o IGN, http://www.ign.es/ign/es/IGN/home.jsp. Este organismo, dependiente del Ministerio de Fomento del Gobierno de España, es uno de los principales distribuidores de información geográfica española en formato digital (ESPIAGO, BAENA, 1997: p. 24). Dentro de la página, debemos pinchar en CNIG. Centro Nacional de Información Geográfica. De ese modo, accedemos a la página de esta última entidad, adscrita al IGN. Acto seguido, hacemos click en Descargas/ Datos. Por último, escogemos el séptimo dato, de nombre MAPA DE ESPAÑA A ESCALA I:2.000.000, pulsando sobre Descargar Documento (vid. fig. 3). A este mapa se le suele denominar BCN2000, ya que consiste en una Base Cartográfica Numérica, es decir, una base de datos representada geográficamente que dispone de información de diversos temas (ESPIAGO, BAENA, 1997: p. 28). Para nuestra investigación hemos adquirido la capa "NUCL2000. DGN", aquella que contiene los municipios de España. Estos últimos servirán para comprobar que los puntos de la malla Localidades_de_ la_ruta_de_Córdoba_a_Toledo.shp han sido adecuadamente georreferenciados. El cuarto dato del módulo para la descarga de datos de la página web del CNIG nos será de utilidad para presentar las rutas óptimas sobre él, pues se trata del MAPA DIGITAL DE ESPAÑA A ESCALA 1:1.250.000. En aras a descargarlo, pinchamos en Descargar Documento y obtenemos la capa ráster "millon.ECW". 


\section{CÓMO IMPLEMENTAR EL SIG}

La plataforma SIG que vamos a utilizar para el cálculo de las rutas óptimas es ArcGIS Desktop 9.2 con la licencia Arclnfo, justamente, aquella que incluye todas las funcionalidades existentes en la versión 9.2. Dicho software ha sido producido por la compañía californiana Environmental Systems Research Institute o ESRI, la cual es una de las empresas más importantes del sector desde finales de la década de 1960 (TOLEDANO, 2004: p. 26).

El primer paso del procedimiento que vamos a desarrollar es obtener las coordenadas en la proyección UTM de las seis localidades que se atravesaban a lo largo del trazado de Córdoba a Toledo, según Ibn Hawqal. Para ello, entramos en el programa Google Earth 5.I y buscamos uno de los asentamientos, por ejemplo, Córdoba. En el caso de la capital del califato, el punto que queremos georrereferenciar es el Bāb Tulayțula, pues la ruta a Toledo partía de esa puerta. Dentro de la Península Ibérica, la coordenada " $x$ " son los metros al Este y la coordenada "y" los metros al Norte (vid. fig. 4). En los dos casos, habrá que redondear las cifras para que no haya decimales. A continuación, buscamos Toledo. Durante el periodo andalusí, el acceso a dicha ciudad se realizaba a través de la Puerta de Alcántara (RAMíREZ DE ARELLANO, 1919: pp. 5-12), por el extremo oriental de la muralla toledana. El puente localizado frente a la puerta, denominado al-qanțara en árabe, permitía cruzar el río Tajo a mediados del siglo X (RÍOS, 1976: pp. 198-20I). En consecuencia, se ha tomado a la mencionada puerta como base para las coordenadas (vid. fig. 5). El resto de localidades que hemos georreferenciado han sido Caracuel de Calatrava, Calatrava la Vieja, Malagón y Los Yébenes. En el caso de estas cuatro, el punto que hemos tomado en consideración para las coordenadas ha sido el centro de cada una de ellas.

Después, vamos a crear las bases de datos de las capas que contendrán los puntos vectoriales, aquellos que representan la ubicación de las seis localidades. En este sentido, entramos en la herramienta ArcCatalog y pulsamos, con el botón derecho del ratón, sobre la carpeta en la que queramos guardar las bases de datos. En nuestro caso, se trata de la denominada Localidades. A continuación, pinchamos en Newl dBASE Table (vid. fig. 6). De este modo, hemos establecido una base de datos, a la que llamaremos "Base de datos de las localidades de la ruta de Córdoba a Toledo.dbf'. Habrá que crear otras siete bases de datos, a las que vamos a denominar "Base de datos de Córdoba y Toledo. dbf", "Base de datos de Córdoba.dbf", "Base de datos de Caracuel.dbf", "Base de datos de Calatrava.dbf", "Base de datos de Malagón.dbf", "Base de datos de Yébenes.dbf" y "Base de datos de Toledo.dbf".

Las capas de los puntos vectoriales las crearemos en la herramienta ArcMap. Por ello, la abrimos y hacemos click en el icono de Add Data (vid. fig. 7), modo en el cual podemos ir cargando las ocho bases de datos, tras seleccionarlas una por una y pinchar en Add. El resultado de este proceso es que podemos hacer uso de todas las bases de datos. De cara a insertar las coordenadas en las bases de datos, pulsamos sobre Base de datos de las localidades de la ruta de Córdoba a Toledo.dbf con el botón derecho del ratón y seleccionamos Open (vid. fig. 8). Acto seguido, debemos pinchar en Options/Add Field.... Llamaremos a la columna Localidad y la rellenaremos con Text (vid. fig. 9). Mediante el mismo procedimiento, creamos las columnas Xcoord e Ycoord. La diferencia con la primera es que el tipo de información con el que las rellenaremos no es texto, sino Long Integer. Por otro lado, eliminaremos la columna Field I haciendo clic en ella con el botón derecho del ratón y eligiendo Delete Field (vid. fig. I0). Antes de rellenar las columnas, es necesario activar el módulo Editor pulsando sobre Start Editing (vid. fig. I I). Tras haber escrito en las tres columnas los nombres de las localidades y sus coordenadas (vid. fig. 12), guardamos lo rellenado con Save Edits y evitamos que esos datos puedan ser cambiados a través de Stop Editing.

En este momento, podemos crear los puntos vectoriales georreferenciados de las seis localidades que forman parte del camino. Para ello, pinchamos en Tools/Add XY Data... (vid. fig. 13) y seleccionamos Base de datos de las localidades de la ruta de Córdoba a Toledo.dbf. 
Debemos rellenar el campo " $x$ " con Xcoord y el campo " $y$ " con Ycoord. La capa vectorial que vamos a elaborar no posee un sistema de referencia para las coordenadas, por lo que hay que elegir uno pulsando sobre Edit.... A continuación, hacemos click en Import... e importamos el sistema de referencia de una malla vectorial georreferenciada. Se ha seleccionado una de las capas cuyo Datum o sistema de referencia es World Geodetic System 84 o WGS84, aquel que utilizaremos a lo largo de toda la investigación. Seleccionamos Aceptar y luego OK (vid. fig. 14). De este modo, hemos creado la capa de puntos vectoriales (vid. fig. I5). Pese a ello, esta malla aún no se ha guardado, para lo cual pinchamos con el botón derecho del ratón en Base de datos de las localidades de la ruta de Córdoba a Toledo Events. Acto seguido, hacemos click en Data/Export Data.... Dentro de la ventana Export Data, pulsamos sobre el icono, esto es, el dibujo de una carpeta abriéndose, de Output shapefile or feature class (vid. fig. 16) y nombramos a la capa vectorial "Localidades_de_la_ruta_de_Córdoba_a_Toledo. shp". Esta malla creada la guardaremos a través de Save en la carpeta Localidades. Después, hacemos click en OK y respondemos No a la pregunta. El procedimiento que hemos seguido hasta ahora habrá que repetirlo con el resto de las bases de datos, incorporando las coordenadas que a cada localidad corresponde y creando las capas de los puntos vectoriales que representan a dichos asentamientos.

Para terminar con las capas vectoriales que representan las localidades que cruzó lbn Hawqal en su itinerario de Córdoba a Toledo, comprobaremos que la georreferenciación de los puntos ha sido precisa. Para ello, en la herramienta ArcMap cargamos, junto a la malla Localidades_de_la_ruta_de_Córdoba_a_Toledo.shp, aquella denominada "NUCL2000.DGN". Esta última la hemos obtenido con las localidades ya georreferenciadas. La superposición de las dos capas demuestra que aquellos municipios que aparecen en la segunda malla, es decir, Córdoba, Malagón, Los Yébenes y Toledo, coinciden perfectamente con las coordenadas que hemos asignado a estos cuatro puntos vectoriales, por lo que se ha podido confirmar una georreferenciación correcta (vid. fig. 17).
El segundo paso del procedimiento es realizar una superficie de fricción de la orografía. Para ello, abrimos la herramienta ArcMap y cargamos el MDT en formato ráster"srtm_36_05. tif" (vid. fig. 18). A continuación, comenzamos a utilizar el módulo Spatial Analyst y pinchamos en Surface Analysis/Slope (vid. fig. 19). Debemos seleccionar Percent y pulsar sobre el icono de Input surface para elegir una carpeta, en nuestro caso MDT, en la cual vamos a guardar la nueva capa. Llamaremos a esta última "pendiente", confirmando dicha denominación al pinchar en Save y, posteriormente, en OK. De esta manera, habremos obtenido una capa de tipo ráster que representa la pendiente en porcentaje. Acto seguido, vamos a reclasificar esta malla, para lo cual es necesario usar, una vez más, el módulo Spatial Analyst. En primer lugar, pulsamos sobre Reclassify... y, dentro de la nueva ventana, pinchamos en el icono de Output raster. Denominaremos a la nueva capa "rec_pendiente" y la guardaremos en la carpeta MDT. Volviendo a la ventana anterior, hacemos click en Classify.... Seleccionamos la opción de 10 clases, esto es, la escala de valores discurrirá del I al 10 (vid. fig. 20). Finalmente, pulsamos sobre OK y, otra vez, sobre OK. En definitiva, hemos elaborado otra malla en formato ráster, aquella que reclasifica los datos de la capa pendiente del modo en el que hemos establecido.

El siguiente paso del procedimiento será elaborar la superficie de fricción de la red hidrográfica. En este sentido, dentro de ArcMap cargamos las capas vectoriales "ESP_water_lines_dcw. shp" y "ESP_water_areas_dcw.shp", aquellas que se conservan en la carpeta Red hidrográfica (vid. fig. 2I). Utilizaremos el módulo Spatial Analyst, pulsando sobre Convert/Features to Raster. Acto seguido, seleccionamos ESP_water_lines_dcw y Shape_Leng, ya que, a la hora de establecer el grado de dificultad de atravesar los distintos ríos españoles, tomaremos en cuenta su longitud. La nueva capa ráster la guardaremos en la carpeta Red hidrográfica, para lo cual pulsamos sobre el icono de Output raster. Llamaremos a la malla creada "ráster_ríos" y pinchamos en Save. Las dimensiones de las celdas habrá que disminuirlas, pues el tamaño que viene predeterminado imposibilitaría un adecuado cálculo de la ruta óptima. Hemos barajado distintas dimensiones, 
y, finalmente, optamos por el tamaño de 0,01. Mediante el clic en OK (vid. fig. 22), se crea definitivamente la malla ráster de los ríos de España. Después, debemos repetir el proceso con la malla vectorial ESP_water_areas_dcw. shp. La capa de tipo ráster resultante, denominada "ráster_lagos", la guardaremos en la misma carpeta que la anterior, adoptando las mismas dimensiones de las celdas. La única diferencia consistirá en el campo que tomaremos en cuenta, porque no se dispone de la denominada Shape_Leng. Por ello, optaremos por el campo ISO, uno de los que no varía, ya que hemos decidido otorgar a todos los lagos españoles el mismo valor. Esta malla ráster representa a los lagos españoles. La elaboración de las mallas ráster de los ríos y los lagos posibilita que los valores de las dos puedan ser unificados en una sola malla. Previamente, debemos reclasificarlas usando el módulo Spatial Analyst y pinchando en Reclassify.... Respecto a ráster_ríos, utilizaremos una escala de valores del I al 10, además de que transformaremos NoData en 0 (vid. fig. 23). De este modo, todos los píxeles de la malla poseen valores y posibilita que la suma de éstos con los de la capa de los lagos no sea errónea. Por último, guardamos la malla ráster de los ríos reclasificada, denominándola "rec_rast_rios", en la carpeta Red hidrográfica. En cuanto a la reclasificación de ráster_lagos, la guardaremos en la misma carpeta que la anterior. El valor I lo cambiaremos por I/ y NoData por 0. La nueva capa de tipo ráster se llama "rec_rast_lag". La superficie de fricción de la red hidrográfica se conseguirá sumando los valores de rec_rast_rios y rec_rast_lag. Para ello, utilizaremos el módulo Spatial Analyst a través de Raster Calculator.... Acto seguido, sumamos las dos capas mencionadas y hacemos click en Evaluate (vid. fig. 24). En consecuencia, hemos elaborado una capa llamada Calculation. Dicha malla no está guardada, por lo que, con el botón derecho del ratón, pulsamos sobre Calculation. A continuación, pinchamos en Save As Layer File... (vid. fig. 25) y nombramos a la capa "Fricción hidrografía.lyr", tras lo cual la guardaremos en la carpeta Red hidrográfica.

El cuarto paso del procedimiento consiste en combinar los costes de las dos superficies de fricción. En este sentido, se utiliza como base la superficie de fricción de la orografía, ya que su coste será dominante sobre la de la red hidrográfica. En primer lugar, abrimos la herramienta ArcMap y cargamos las mallas rec_pendiente y Fricción hidrografía.lyr. Después, elegimos el módulo Spatial Analyst para hacer uso de Raster Calculator. La fórmula que hemos aplicado es la siguiente:

[rec_pendiente]+([Fricción hidrografia.lyr] ${ }^{*}$ |/ / 00)

La capa creada se denomina Calculation 2. Acto seguido, la guardaremos bajo el nombre de "Fricción orografía e hidrografía.lyr" en la carpeta que hemos denominado Ruta óptima.

El quinto paso supone el último en la elaboración del modelo predictivo del trazado que existiría entre Córdoba y Toledo a mediados del siglo X. Precisamente, vamos a calcular el camino de menor coste entre esas dos ciudades. Para ello, abrimos la herramienta ArcMap y cargamos los puntos vectoriales Córdoba. shp y Toledo.shp y la capa Fricción orografía e hidrografía.lyr. A continuación, empezamos a usar el módulo Spatial Analyst y pinchamos en Distance/Cost Weighted.... La distancia se medirá respecto a Córdoba y seleccionaremos Calculation2 como superficie de fricción. Asimismo, nos interesa crear una capa que tome en cuenta la dirección, ya que se trata de un modelo anisotrópico. Por ello, haremos click junto a Create direction. El nombre que elegiremos para dicha malla ráster será "costdireccion" y la guardaremos dentro de la carpeta Camino de menor coste, tras haber pulsado sobre el icono de Create direction. En la misma carpeta guardaremos la capa ráster "costdistancia" tras pinchar en el icono de Output raster. Finalmente, hacemos click en OK (vid. fig. 26). De esta manera, en base a la superficie de combinación de costes de la orografía y la red hidrográfica, hemos creado dos capas en formato ráster. La creación de estas dos mallas posibilita el cálculo del camino de mínimo coste de Córdoba a Toledo. En este sentido, elegimos el módulo Spatial Analyst y hacemos click en Distance/ Shortest Path... Tendremos que apuntar que el punto de llegada corresponde con Toledo, además de que las capas del coste de la distancia y de la dirección equivalen a Costdistancia y 
Costdireccion, respectivamente. El resultado del cálculo lo guardaremos en la carpeta Camino de menor coste y pincharemos en OK (vid. fig. 27). La nueva capa se denomina "Camino de menor coste Córdoba Toledo con orogr-hidrogr. shp" y se trata de una polilínea vectorial (vid. fig. 28). Una de las opciones más interesantes es observar dicho camino de mínimo coste superpuesto a la malla "millon.ECW', capa que se encuentra en la carpeta Camino de menor coste y que representa el mapa de España, por lo que sirve para comparar la red viaria actual con la del periodo califal.

El siguiente paso consiste en la comparación del camino de mínimo coste entre Córdoba y Toledo y los itinerarios propuestos por Félix Hernández e Ibn Hawqal. Si atendemos al trazado descrito por el geógrafo musulmán, su precisión respecto al modelo predictivo que hemos elaborado se puede observar cargando la capa de puntos vectoriales Localidades_de_la_ruta_de_Córdoba_a_Toledo.shp. De acuerdo con ella, Caracuel y Malagón se sitúan dentro del trazado de la ruta óptima, a la vez queYébenes se localiza a escasa distancia de dicho itinerario. En el caso de Calatrava, su posición es algo más lejana del camino de mínimo coste, aunque se encuentra relativamente cerca (vid. fig. 29).

Para comparar el modelo predictivo con la vía expuesta por Félix Hernández, necesitamos cargar la capa ráster que posee la denominación "Camino de Félix Hernández.jpg" (vid. fig. 30). Este mapa hay que georreferenciarlo, para lo cual utilizaremos el módulo Georeferencing. Primero, pulsamos sobre el icono Add Control Points (vid. fig. 3I). Acto seguido, debemos unir los cinco puntos del mapa que coinciden con los puntos vectoriales de la capa Localidades_ de_la_ruta_de_Córdoba_a_Toledo.shp. Se trata de los asentamientos de Córdoba, Caracuel, Calatrava, Malagón y Toledo. A modo de ejemplo, en las siguientes imágenes mostramos la unión en la capital andalusí (vid. fig. 32). Tras el nexo de todos los puntos, la georreferenciación habrá sido completada. Para guardar los cambios llevados a cabo en el mapa, debemos pinchar en Georeferencing/Update Georeferencing. La comparación del modelo predictivo con el trazado propuesto por Félix Hernández demuestra que los dos caminos son completamente distintos y no tienen ningún punto en común (vid. fig. 33). Ciertamente, parece poco probable que la vía califal de Córdoba a Toledo coincidiese con el itinerario apuntado por el arquitecto barcelonés. El trazado descrito por Ibn Hawqal, en cambio, posee dos localidades que son atravesadas por la ruta óptima obtenida a través de la herramienta SIG, mientras que las otras dos se sitúan cerca de la polilínea vectorial. En conclusión, el modelo predictivo fundamenta que la ruta del geógrafo musulmán debía de ser aquella que existía a mediados del siglo $X$.

El séptimo paso del procedimiento se basa en matizar el camino por el que viajó lbn Hawqal entre Córdoba y Toledo, partiendo de las seis localidades del itinerario acerca de las que nos informó el geógrafo musulmán. Para ello, abrimos la herramienta ArcMap y cargamos los puntos vectoriales Córdoba.shp, Caracuel. shp, Calatrava.shp, Malagón.shp, Yébenes.shp y Toledo.shp y la capa ráster Fricción orografía e hidrografía.lyr. A continuación, utilizaremos el módulo Spatial Analyst para calcular el camino de menor coste entre los dos puntos vectoriales más próximos, habiendo obtenido los cinco tramos de la vía califal. El método que hemos desarrollado es el mismo que ejecutamos para crear Camino de menor coste Córdoba Toledo con orogr-hidrogr.shp. En aras a la consecución de las cinco rutas óptimas, hemos creado las capas ráster "costdistramo2", "costdirtramo2", "costdistramo3", "costdirtramo3", "costdistramo4", "costdirtramo4", "costdistramo5" y "costdirtramo5", guardándolas en la carpeta Ruta óptima. Respecto al primer tramo del itinerario de lbn Hawqal, no era necesario crear las superficies de coste de la distancia y de la dirección, pues hemos cargado costdistancia y costdireccion, dos de las mallas ya existentes. Finalmente, hemos obtenido los cinco tramos del camino, en forma de las polilíneas vectoriales "Camino de menor coste Córdoba Caracuel.shp", "Camino de menor coste Caracuel Calatrava.shp","Camino de menor coste Calatrava Malagón.shp","Camino de menor coste Malagón Yébenes" y "Camino de menor coste Yébenes Toledo.shp" (vid. fig. 34). Dichas capas se encuentran en la carpeta Ruta 
óptima. El resultado obtenido mediante la unión de los cinco tramos es bastante esclarecedor: el camino de menor coste que tiene en cuenta los puntos intermedios mencionados por el geógrafo musulmán coincide en prácticamente todo el trazado con el que únicamente considera el origen y el destino de la vía de Córdoba a Toledo (vid. fig. 35).

Por último, hemos cargado la malla ráster millon.ECW en la herramienta ArcMap, superponiendo sobre ella las cinco polilíneas vectoriales que simbolizan el camino de menor coste entre la capital andalusí y la ciudad a orillas del río Tajo, de acuerdo con lo expuesto por lbn Hawqal. Asimismo, hemos representado dicho camino sobre el MDT, la red hidrográfica y las localidades que han condicionado su elaboración (vid. fig. 36).

\section{FORTALEZAS Y DEBILIDADES DE LA METODOLOGÍA APLICADA}

El modelo predictivo que hemos elaborado posee una sólida labor de investigación, aquella que ha precedido a la digitalización y almacenamiento de los datos. Ese trabajo de documentación ha sido facilitado gracias a la accesibilidad de las fuentes: por un lado, la obra geográica de Ibn Hawqal y el artículo de Félix Hernández se encuentran disponibles en castellano; por otro lado, se ha podido precisar la localización de los distintos asentamientos y puertas mediante el uso de Google Earth. Finalmente, la información geográfica digital se ha obtenido en Internet, a través de los servidores que tanto instituciones públicas como privadas han puesto en marcha.

En segundo lugar, hemos cumplido dos de los tres objetivos que nos habíamos propuesto inicialmente. La primera meta que nos habíamos marcado era calcular el camino de menor coste entre Córdoba y Toledo, lo cual permitiría analizar la viabilidad que potencialmente tendrían los itinerarios descritos por Ibn Hawqal y Félix Hernández. Tras el análisis, los resultados apuntan a que el trayecto del geógrafo musulmán es mucho más viable que el del arquitecto barcelonés. El segundo propósito trataba de matizar el trazado que debió de recorrer Ibn Hawqal, aquello que se obtendría mediante el cálculo de los trayectos de mínimo coste entre las localidades intermedias de la vía descrita por este último. La unión de los distintos tramos del itinerario evidencia que el trazado es prácticamente idéntico al del camino que no toma en consideración los asentamientos intermedios.

El tercer punto fuerte del estudio, y el más destacable a su vez, consiste en que la investigación desarrollada supone una importante aportación para la Arqueología Medieval. Durante el diseño del estudio apuntábamos que, en cuanto al registro material, conocíamos escasamente la red viaria andalusí. Precisamente, hasta la actualidad se han localizado muy pocos puentes y tramos de los caminos que partían de Córdoba a mediados del siglo $X$. El modelo predictivo del itinerario de menor coste entre la capital andalusí y Toledo posibilita la delimitación del área en el cual se comenzarán a hacer prospecciones para identificar la vía y los puentes. Respecto al debate historiográfico existente acerca del trazado del camino califal entre las dos ciudades mencionadas, nuestra investigación ofrece nuevos datos a los historiadores especializados en el estudio de al-Andalus. En este sentido, la ruta propuesta por Ibn Hawqal y Évariste LéviProvençal se postula como aquella que debió de existir en el califato de Córdoba.

El proyecto también poseía varios puntos débiles que aún no han sido resueltos. Uno de ellos es «la falta de técnicos informáticos cualificados» (RUBIO, 2007), problema que ya había sido planteado por Xabier Rubio Campillo en su trabajo sobre el uso de una plataforma SIG en el análisis histórico. Dentro de la investigación que hemos llevado a cabo, la falta de personal especializado en Ingeniería Informática se ha traducido en la incapacidad de cumplir el tercer objetivo propuesto. Ciertamente, no hemos podido verificar si es posible realizar los distintos tramos del trayecto en el plazo marcado por Ibn Hawqal. A pesar de conocer el algoritmo de movilidad de Gorenflo y Gale y las distintas variables que en él influían, nuestros conocimientos eran insuficientes a la hora de 
aplicar la fórmula. Dicha deficiencia formativa se podría solucionar mediante la colaboración de un equipo de investigación que cuente con este tipo de técnicos entre sus miembros.

Otra de las debilidades de nuestra investigación es que los resultados obtenidos a través de la herramienta SIG poseen un carácter orientativo (LÓPEZ, 2005: p. 109), pues posteriormente habrá que comprobar sobre el terreno la precisión de los modelos predictivos creados. Asimismo, los estudios que utilizan un SIG no suelen estar exentos de errores o limitaciones que distorsionan los resultados finales. En el caso del cálculo de la ruta óptima entre Córdoba y Toledo, la capa ESP_water_areas_dcw.shp representa los embalses y lagos españoles. Los primeros son grandes depósitos de agua artificiales que no existían en el siglo X. A modo de ejemplo, disponemos del embalse de Buendía, el cual se formó en 1958. Por ello, su inclusión en la superficie de fricción de la red hidrográfica supone una deformación de los costes reales para cruzar dicha capa. La solución al problema podría llegar mediante la creación de un campo en la tabla de atributos que clasificase los depósitos de agua según son lagos o embalses. Pese a todo, la capa no conoce muchos de los nombres de los depósitos, por lo que dificulta enormemente la clasificación.

Por último, el tercer punto débil de la metodología que hemos desarrollado en el trabajo está totalmente relacionado con los problemas inherentes al uso de un SIG. Ciertamente, la resolución de las capas y las fórmulas introducidas en la calculadora de mapas son seleccionadas de un modo arbitrario por parte de los usuarios del Sistema de Información Geográfica (BAENA, 2003). Si atendemos a la resolución que hemos elegido a la hora de elaborar las mallas ráster_ríos y ráster_lagos, ésta es distinta a la que la herramienta introducía por defecto. Para obtener un resultado lo suficientemente fiable, había que reducir el tamaño de las celdas, seleccionando las dimensiones que hemos considerado más adecuadas. En cuanto a la fórmula para obtener la capa Fricción orografía e hidrografía.lyr, probamos con varias funciones, hasta que estimamos que aquella era la que mejor reflejaba la proporción de cada coste.

\section{CONCLUSIONES}

La investigación que hemos efectuado ha constatado lo siguiente: el modelo predictivo obtenido mediante el uso de la herramienta SIG plantea que el camino descrito por lbn Hawqal era la vía califal que comunicaba Córdoba con Toledo a mediados del siglo X, cuyo trazado hemos podido matizar en gran medida. Este resultado revela que las posibilidades de análisis que ofrece la herramienta SIG son múltiples y no han sido aún ampliamente utilizadas por parte de los arqueólogos e historiadores especializados en la Edad Media. Asimismo, el resultado demuestra que la información que aportan las fuentes textuales directas no tiene porqué contradecirse con la ofrecida por los modelos predictivos generados mediante un SIG. Al contrario, los datos de estas diversas fuentes pueden ser complementarios, siendo el uso de todos ellos indispensable para el conocimiento de algunas materias, como prueba el presente estudio.

La primera parte de la investigación la hemos destinado a integrar la ruta entre la capital andalusí y la ciudad a orillas del río Tajo a su entorno físico. La comparación con los itinerarios propuestos por Félix Hernández Giménez e Ibn Hawqal ha demostrado que la viabilidad del camino del geógrafo musulmán es mucho mayor que el del arquitecto barcelonés. Desde mediados del siglo XX, el debate historiográfico había contado con especialistas en al-Andalus que habían apoyado una u otra propuesta. El presente modelo predictivo aporta nuevos datos a favor de la vía descrita por Ibn Hawqal y Évariste Lévi-Provençal. En el segundo apartado del artículo, sugeríamos que debíamos apostar por la veracidad de la fuente textual directa, esto es, la obra escrita por el geógrafo musulmán en la segunda mitad del siglo X. Finalmente, el resultado del análisis apunta en la misma dirección.

Después de haber optado por el camino de Ibn Hawqal, había que matizar el trazado de dicha vía, pues solamente conocíamos seis de las localidades por las que ésta transcurría. El cálculo de los caminos de mínimo coste entre dichos asentamientos nos ha llevado a 
aseverar que el itinerario obtenido mediante este procedimiento coincide en la mayor parte de su trazado con aquel que solamente tomaba en cuenta los puntos de origen y destino, es decir, Córdoba y Toledo. La única localidad que se aleja bastante del itinerario de menor coste entre las capitales omeya y visigoda es Calatrava, «gran ciudad» (vid. anexo I) que representa un polo de atracción lo suficientemente fuerte como para desviar ligeramente el camino óptimo. En cuanto al tramo entre Córdoba y Caracuel, Ibn Hawqal nos informa sobre su paso por tres localidades de las que no menciona el nombre. Su conocimiento permitiría precisar en mayor medida el itinerario califal de Córdoba a Toledo, ya que la primera mitad de éste nos es completamente desconocido, de no ser por el modelo predictivo que hemos elaborado. Pese a todo, estimamos que la no mención de las localidades entre la capital andalusí y Caracuel se debe a que eran núcleos de población de escasa importancia, por lo que su ubicación sería, en gran medida, acorde con el camino de mínimo coste. Esto es, al menos, lo que hemos podido comprobar con los asentamientos mencionados entre las capitales omeya y visigoda, salvo en el caso de Calatrava, pues esta última se trata de una localidad de una mayor entidad.

El cálculo de las rutas de mínimo coste se ha realizado tomando en consideración la orografía y la red hidrográfica. Podría plantearse que el estudio se sustenta en un excesivo determinismo geográfico, ya que, a la hora de evaluar los costes de atravesar un terreno, solo se han atendido los factores naturales. Los factores culturales nos eran desconocidos en gran medida, caso de los puentes y los caminos. Justamente, la investigación fue planteada como punto de partida para las prospecciones arqueológicas que se pudiesen ejecutar en busca de dichas estructuras. Asimismo, el hecho de que el itinerario de Ibn Hawqal y el modelo predictivo basado en factores naturales se asemejen nos hace concluir que hemos dispuesto de datos suficientes, cuantitativa y cualitativamente, como para aseverar que el cálculo del camino de mínimo coste realizado debe ser tomado en cuenta en estudios venideros.

\section{Anexo I (HAWQAL, I97 I: p. 69)}

\begin{abstract}
Se emplea cuatro días de Córdoba a Caracuel, ciudad provista de una catedra, mercados, baños y posadas; cada noche se descansa en un pueblo habitado.
\end{abstract}

En una etapa se va de Caracuel a Calatrava, gran ciudad provista de una muralla de piedra, junto a un gran río, cuyos habitantes toman agua potable, utilizándola para la agricultura; hay mercados, baños, establecimientos de comercio; el camino pasa por populosos pueblos.

Una etapa hay de Calatrava a Malagón, ciudad situada junto a un río, defendida por un muro de tierra, inferior en superficie a Calatrava; el río lleva el nombre de la ciudad y suministra agua potable.

Una etapa de allí a Yébenes, pueblo muy poblado, provisto de una posada y de una fuente que da agua potable.

Una etapa de Yébenes a Toledo, gran ciudad famosa y célebre, más importante que Pechina, rodeada de una solida muralla, regada por el Tajo, sobre el cual se encuentra un gran puente de piedra con una longitud de cincuenta brazas; este riachuelo se proyecta en el río que tiene su desembocadura en Cintra.

\section{BIBLIOGRAFÍA}

AL-BAKRT̄, Abū 'Ubayd (1982): Geografía de España (kitāb al-masālik wa-l-mamālik). Introducción, traducción, notas e índices por Eliseo Vidal Beltrán, Zaragoza, Anubar.

BAENA, Javier (2003): "La Arqueología peninsular y los SIG: presente y futuro", Arqueoweb: Revista sobre Arqueología en Internet. En línea, 5, I, 03/0 I/20 I2, acceso disponible en http://www.ucm.es/info/arqueoweb/pdf/5-1/ baena.pdf.

BERMÚDEZ, Jesús (200 I): La aplicación de los Sistemas de Información Geográfica a la Arqueología, Madrid, Universidad Autónoma de Madrid.

BERMÚDEZ, Jesús (2004): "Creación de rutinas o macros con el programa Idrisi: el cálculo acumulado de visibilidades y rutas óptimas", Informática Aplicada a la Investigación y la Gestión Arqueológicas. Córdoba, Servicio de Publicaciones de la Universidad de Córdoba, pp. 407-4I8. 
BURILLO, Francisco; ESCOLANO, Severino; LÓPEZ, Raúl; RUIZ, Enrique (2008): Roma versus Segeda. Una propuesta sobre el camino hispano seguido por el cónsul Nobilior en el año 153 a.C., Zaragoza, Fundación Segeda.

CONOLLY, James; LAKE, Mark (2009): Sistemas de información geográfica aplicados a la arqueología, Barcelona, Bellaterra.

ESPIAGO, Javier; BAENA, Javier (1997): "Los Sistemas de Información Geográfica como tecnología informática aplicada a la Arqueología y a la Gestión del Patrimonio", Los SIG y el análisis espacial en Arqueología. Madrid, Universidad Autónoma de Madrid, pp. 7-65.

FAIRÉN, Sara (2004): "Se hace camino al andar? Influencia de las variables medioambientales y culturales en el cálculo de caminos óptimos mediante SIG", Trabajos de Prehistoria. 61, 2, pp. 25-40.

FERNÁNDEZ, Jesús (2010): "Modelos predictivos y SIG. Algunos ejemplos de su aplicación en Arqueología: los asentamientos fortificados del Valle del Trubia (Asturias, España)", Mapping. 140, pp.76-82.

GARCÍA, L. (2005): Introducción al reconocimiento y análisis arqueológico del territorio, Barcelona, Ariel.

HAWQAL, Muhammad Ibn ( 1873$)$ : Viae et regna: descriptio ditionis moslemicae, Leiden, E.J. Brill.

HAWQAL, Muhammad Ibn (1938): Opus geographicum, Leiden, E.J. Brill.

HAWQAL, Muhammad Ibn (197|): Configuración del mundo (Fragmentos alusivos al Magreb y España). Traducción e índices por María José Romaní Suay, Valencia, Anubar.

HERNÁNDEZ, Félix (1959): "El camino de Córdoba a Toledo en la época musulmana", Al-Andalus. Revista de las Escuelas de Estudios Árabes de Madrid y Granada. 24, I, pp. I-62.

LÉVI - PROVENÇAL, Évariste (1962):" España musulmana. Hasta la caída del Califato de Córdoba $(7|1-103|$ de J. C.). Instituciones y vida social e intelectual", Historia de España. Madrid, Espasa-Calpe, tom. V.

LÉVI - PROVENÇAL, Évariste (1996): "España musulmana. Hasta la caída del Califato de Córdoba (7|1-103| de J. C.)", Historia de España. Madrid, Espasa-Calpe, tom. IV.

LÓPEZ, Raúl (2005): "Cálculo de rutas óptimas mediante SIG en el territorio de la ciudad celtibérica de Segeda. Propuesta metodológica", SALDVIE. 5, pp. 95-III.

MANZANO, Eduardo (2006): Conquistadores, emires y califas: los omeyas y la formación de al-Andalus, Barcelona, Crítica.

PARCERO, César (2002): La construcción del paisaje social en la Edad del Hierro del noroeste ibérico, Santiago de Compostela, Fundación F.M. Ortegalia.

RAMÍREZ DE ARELLANO, Rafael (1919): El Mesón del Sevillano, Toledo, Sebastián Rodríguez.

Resolución de 13 de mayo de 2002 (BOJA núm. 70, 15.6.2002)
RÍOS, José Amador de los (1976): Toledo pintoresca o descripción de sus más célebres monumentos, Barcelona, El Albir.

ROLDÁN, José Manuel (1975): Itineraria hispana. Fuentes antiguas para el estudio de las vías romanas en la Península Ibérica, Madrid, Departamento de Historia Antigua de la Universidad de Valladolid \& Departamento de Historia Antigua de la Universidad de Granada.

RUBIO, Alfonso; GUTIÉRREZ, Javier (1997): "Los Sistemas de Información Geográficos: origen y perspectivas", Revista General de Información y Documentación. 7, I, pp. 93- 106.

RUBIO, Xabier (2007): "Las herramientas SIG Libre en la investigación histórica", I Jornadas de SIG Libre. En línea, Girona, Servicio de Sistemas de Información Geográfica y Teledetección de la Universidad de Girona, 03/0 I/20 I2, acceso disponible en http://www.sigte.udg.edu/jornadassiglibre2007/comun/2pdf/l.pdf

RUIZ-GÁLVEZ, Marisa; GUTIÉRREZ, Javier; TORRES, Mariano: GONZÁLEZ, Alfredo; BASILDO, Rosa; LÓPEZ, Óscar; DÍAZ, Beatriz (2002): "Aproximación al paisaje de la Edad del Bronce en Pranemuru (Cerdeña)", Complutum. I3, pp. 259-280.

TOLEDANO, Miguel (2004): "Orígenes e historia de los SIG", Informática Aplicada a la Investigación y la Gestión Arqueológicas. Córdoba, Servicio de Publicaciones de la Universidad de Córdoba, pp. 19-29.

TORRES, Leopoldo (1959): "La vía Augusta y el arrecife musulmán", Al-Andalus. Revista de las Escuelas de Estudios Árabes de Madrid y Granada. 24, 2, pp. 44I-448.

URIARTE, Antonio (2005): "Arqueología del Paisaje y Sistemas de Información Geográfica: una aplicación en el estudio de las sociedades protohistóricas de la cuenca del Guadiana Menor (Andalucía oriental)", Bronce Final y Edad del Hierro en la Península Ibérica. Encuentro de Jóvenes Investigadores. Salamanca, Fundación Duques de Soria \& Ediciones Universidad de Salamanca, pp. 603-621.

VILANOU, Roger; MUÑOZ, Anna; PÉREZ, Antoni (20I0): "Modelo anisotrópico de cálculo de rutas de coste mínimo con gvSIG y SEXTANTE", IV Jornadas de SIG Libre. En línea, Girona, Servicio de Sistemas de Información Geográfica y Teledetección de la Universidad de Girona, 03/01/2012, acceso disponible en http://www.sigte.udg.edu/jornadassiglibre20 I0/uploads/Articles/a9.pdf .

\section{CONSULTA Y DESCARGA DE LA INFOR- MACIÓN GEOGRÁFICA DIGITAL}

CGIAR-CSI: En línea, 03/0I/2012, acceso disponible en http://srtm.csi.cgiar.org/.

DIVA-GIS: En línea, 03/0I/2012, acceso disponible en http://www.diva-gis.org/.

IGN: En línea, 09/09/2010, acceso disponible en http:// www.ign.es/ign/es/IGN/home.jsp. 


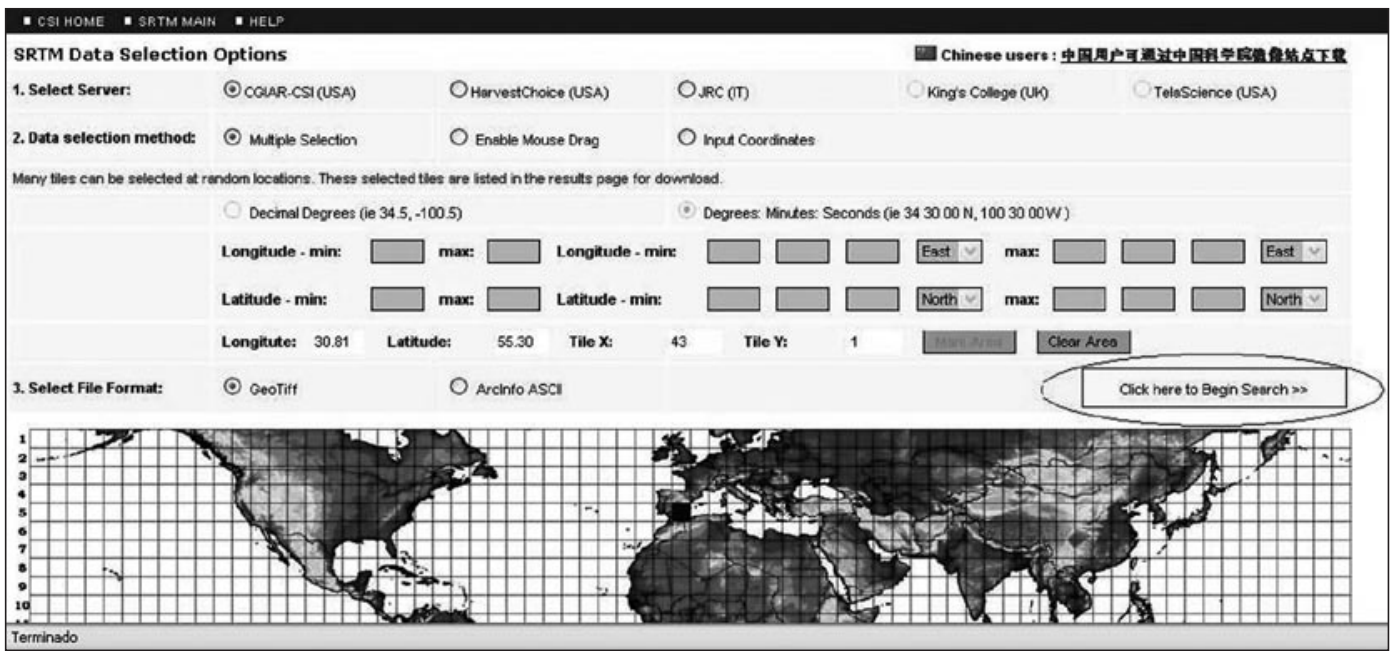

Fig. I. Selección del MDT de la SRTM de la zona Suroriental de la Península Ibérica y pinchar sobre Click here to Begin Search

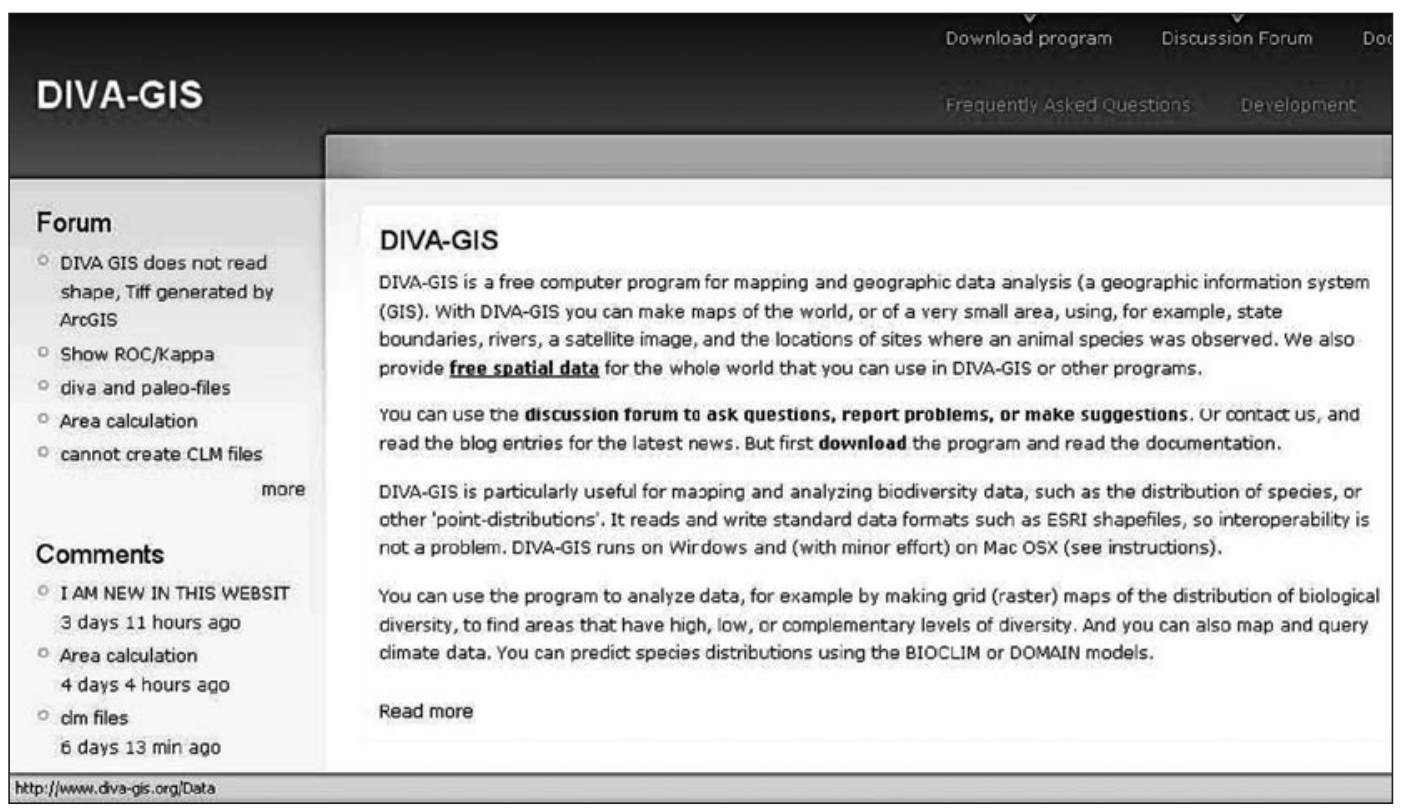

Fig. 2. Pulsar sobre free spatial data en la página web del programa DIVA-GIS

\begin{tabular}{|c|c|}
\hline 覀 Visualizar Pedido & - $P$ Búsqueda Avanzada \\
\hline WEB CNIG & \multirow[t]{3}{*}{ Seleccione al $n^{0}$ de registros que desea visualizar $\Rightarrow 10^{\circ}-20-60-100-500^{\circ}$} \\
\hline Búsqueda Productos & \\
\hline $\begin{array}{l}\text { Fotogiafía aéred e } \\
\text { Imagen Digital }\end{array}$ & \\
\hline Looalizadores & \multirow[b]{2}{*}{\begin{tabular}{|r} 
DATOS \\
\end{tabular}} \\
\hline Calculadora Geodésioa & \\
\hline Desualyas & \multirow{3}{*}{$\begin{array}{l}\text { NOMBRE E IDENTIFICADOR DE LAS HOJAS DE LAS SERIES MTN50 (BCN50) Y MTY25(BCN25) DEL IGNJCNIG } \\
\text { - 160 KB } \\
\text { Contiene los nombres y sus correspondientes números de las hojas en la rejilla VTN } 50 \text { y MTN25 del } \\
\text { IGN/CNIG,así como su correspondencia con las hojas del Servicio Geográfico del jjército (SGE) } \\
\text { Descargar Documento }\end{array}$} \\
\hline CNIG & \\
\hline Información y Venta & \\
\hline $\begin{array}{l}\text { Gestión de usuariosy } \\
\text { pedidos }\end{array}$ & \multirow{4}{*}{ 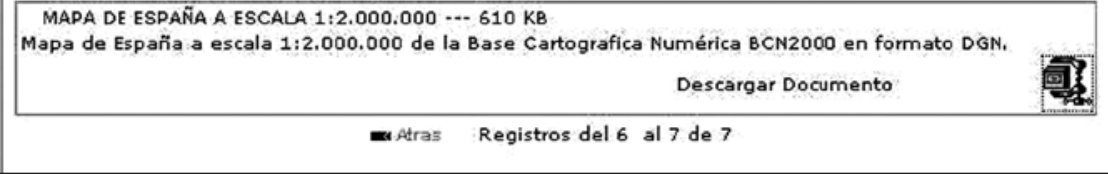 } \\
\hline Foro & \\
\hline Preguntas Frecuentes: & \\
\hline $\begin{array}{l}\text { Búsqueda en } \\
\text { Nomenclátor }\end{array}$ & \\
\hline
\end{tabular}

Fig. 3. Obtención del mapa BCN2000 pinchando sobre el icono de Descargar Documento del séptimo dato 


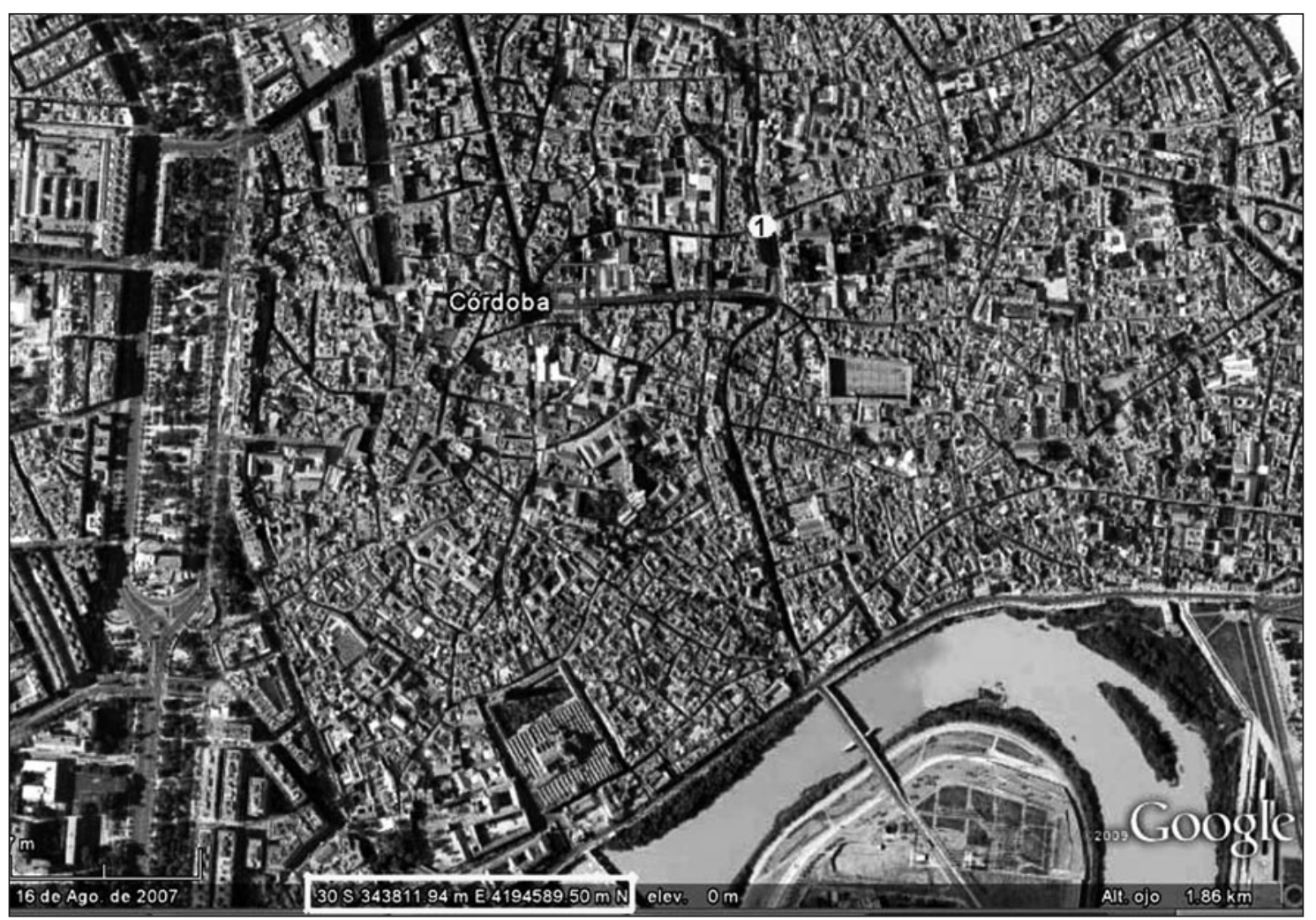

Fig. 4. Córdoba y la localización de la Bāb Tulayțula (I) en coordenadas UTM

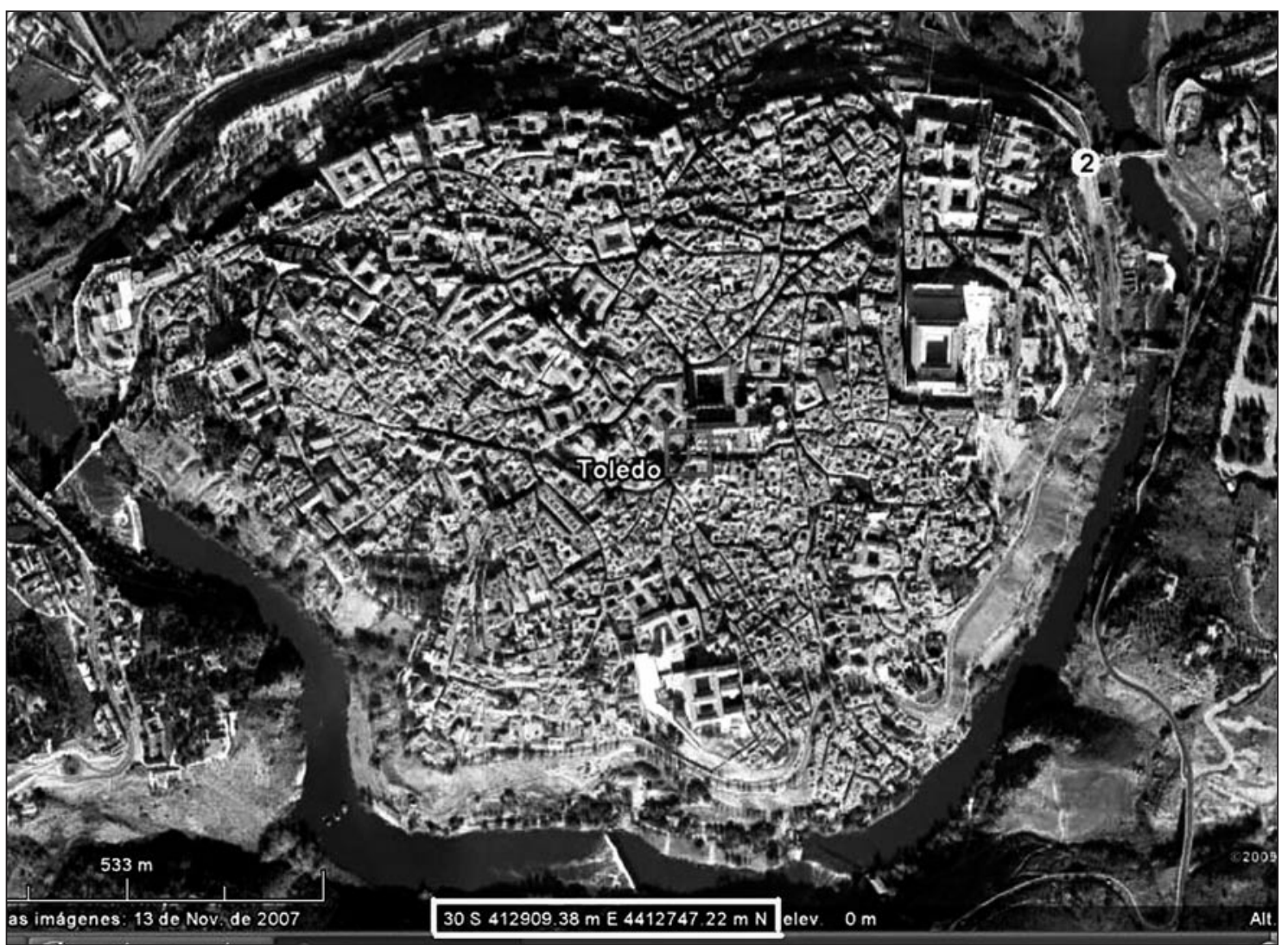

Fig. 5. Toledo y la localización de la Puerta de Alcántara (2) en coordenadas UTM 


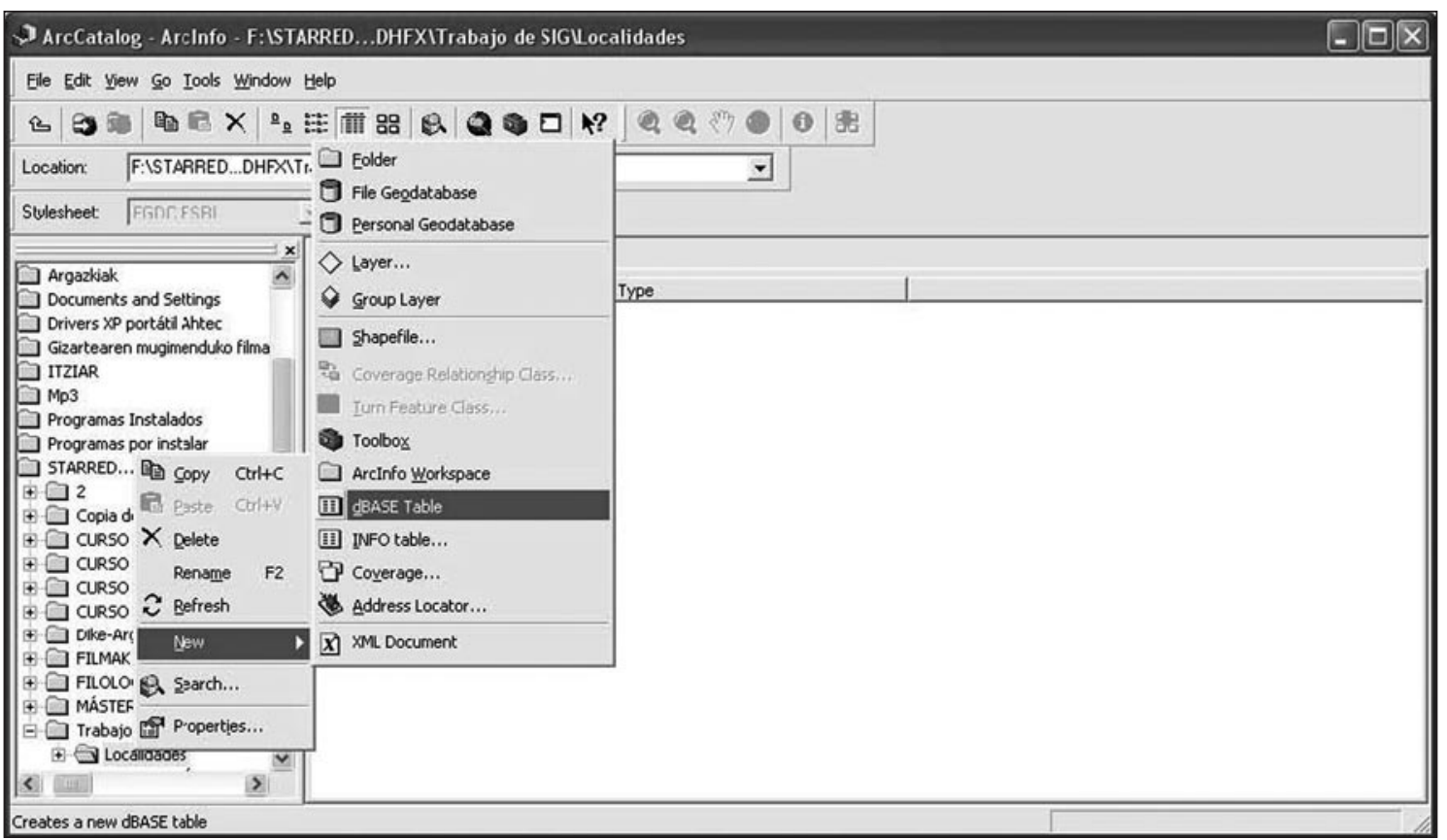

Fig. 6. ArcCatalog permite crear bases de datos haciendo click sobre New/dBASE Table

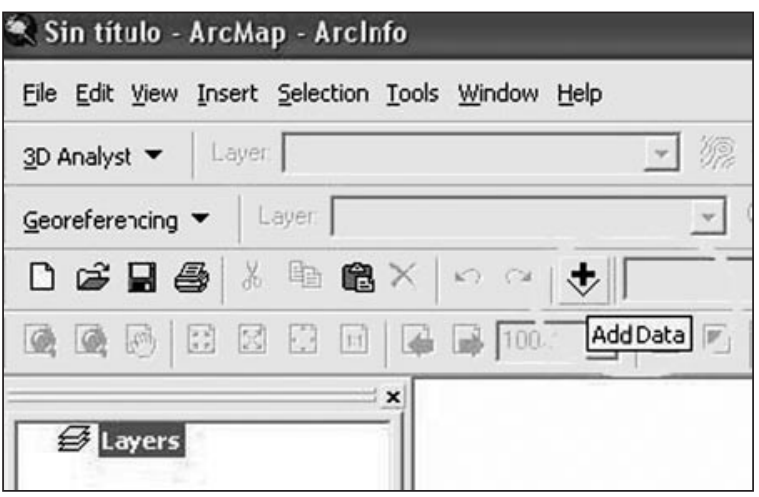

Fig. 7. En ArcMap las capas se abren con el icono de Add Data

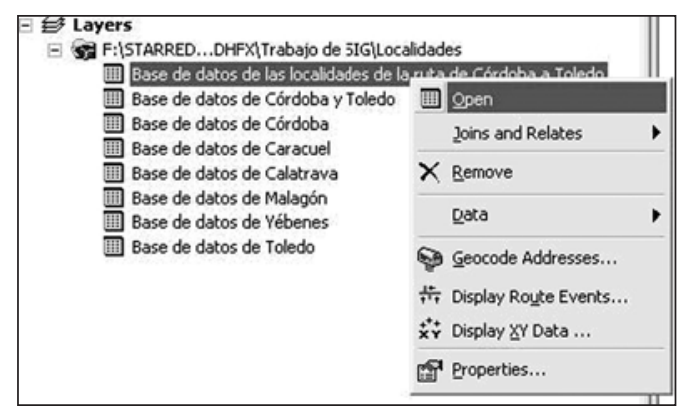

Fig. 8. Pulsar sobre la base de datos con el botón derecho del ratón y seleccionar Open

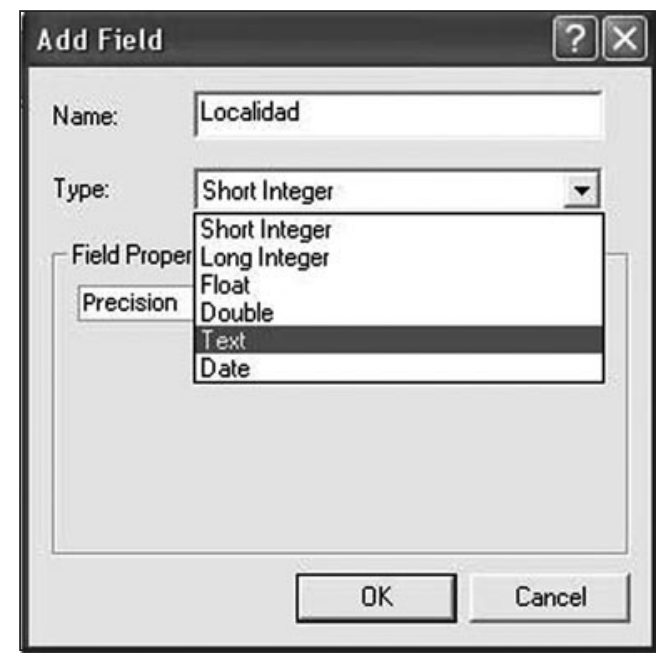

Fig. 9. Nombre de la columna y el tipo de datos que introduciremos en ella será texto

Fig. I0. Eliminar Field I con Delete Field

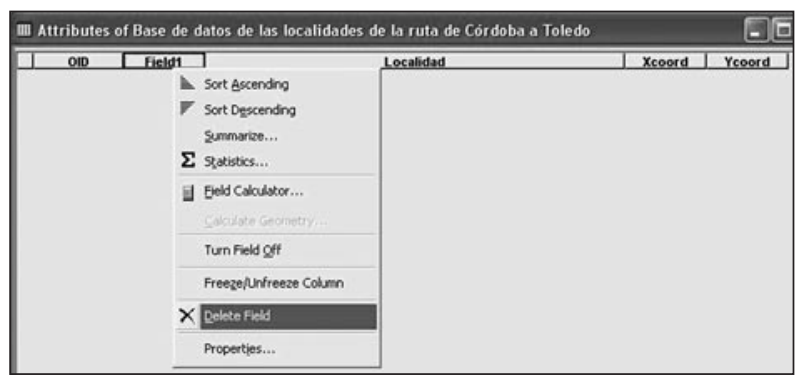




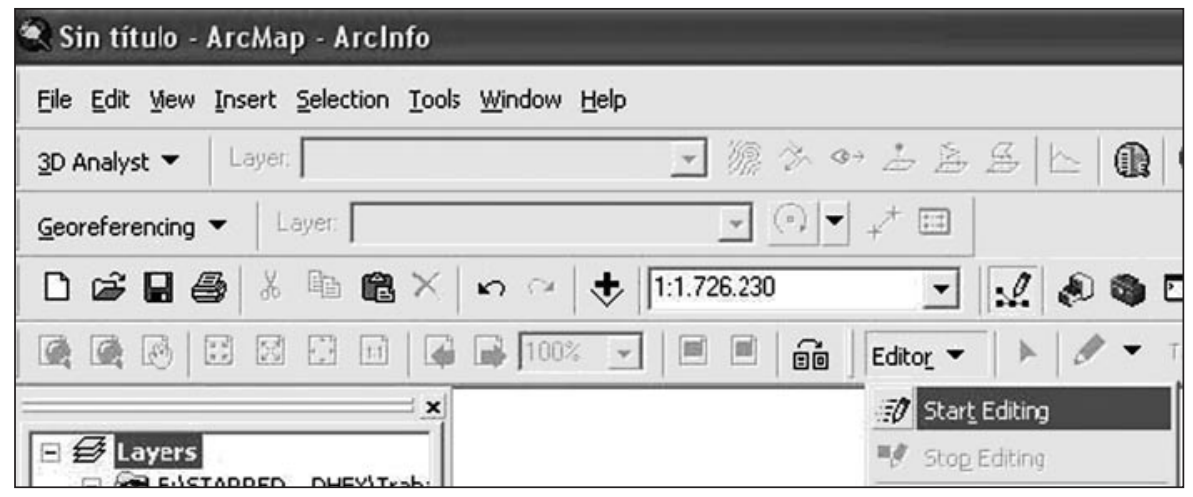

Fig. II. Activación del módulo Editor pinchando en Start Editing

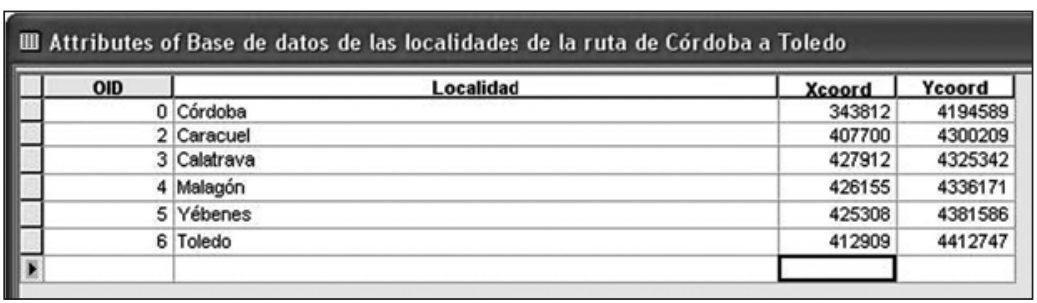

Fig. I2. Base de datos con los nombres de las localidades y sus coordenadas

\section{Q Sin título - ArcMap - ArcInfo}

File Edit View Insert Selection Iools Window Help

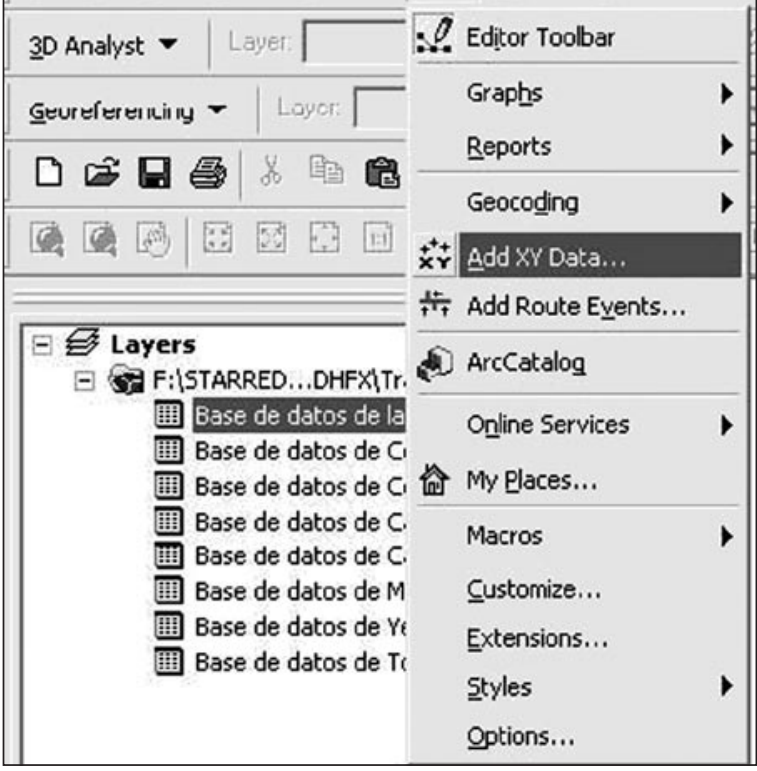

Fig. I3. Hacer click en Tools/Add XY Data

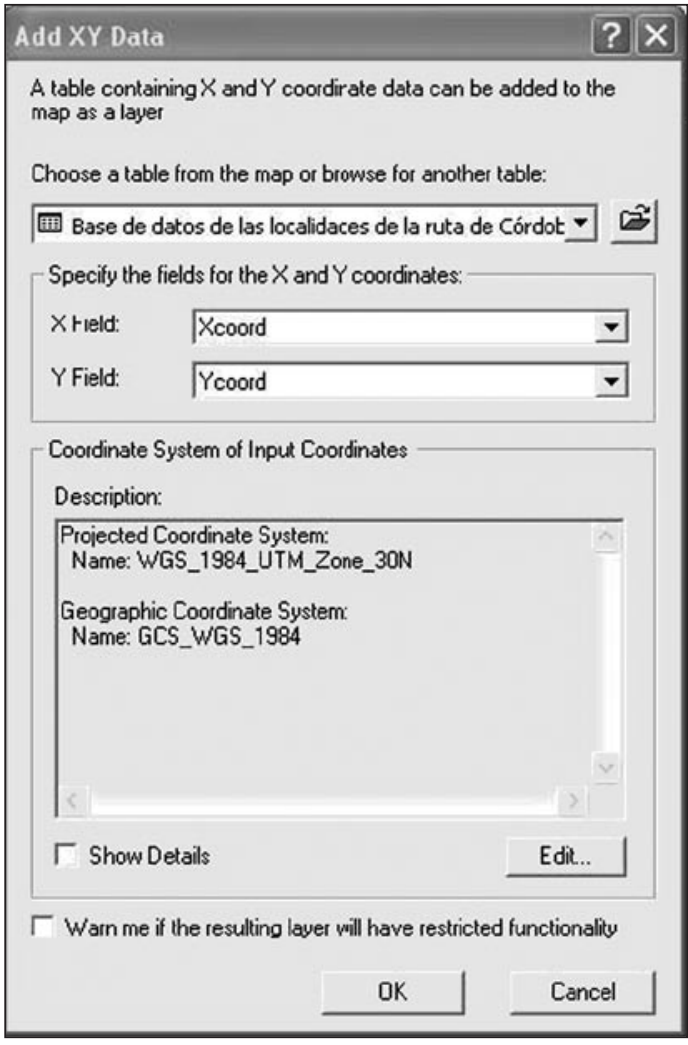

Fig. I4. Tras eleguir el sistema de referencia WGS84, pulsamos sobre OK 


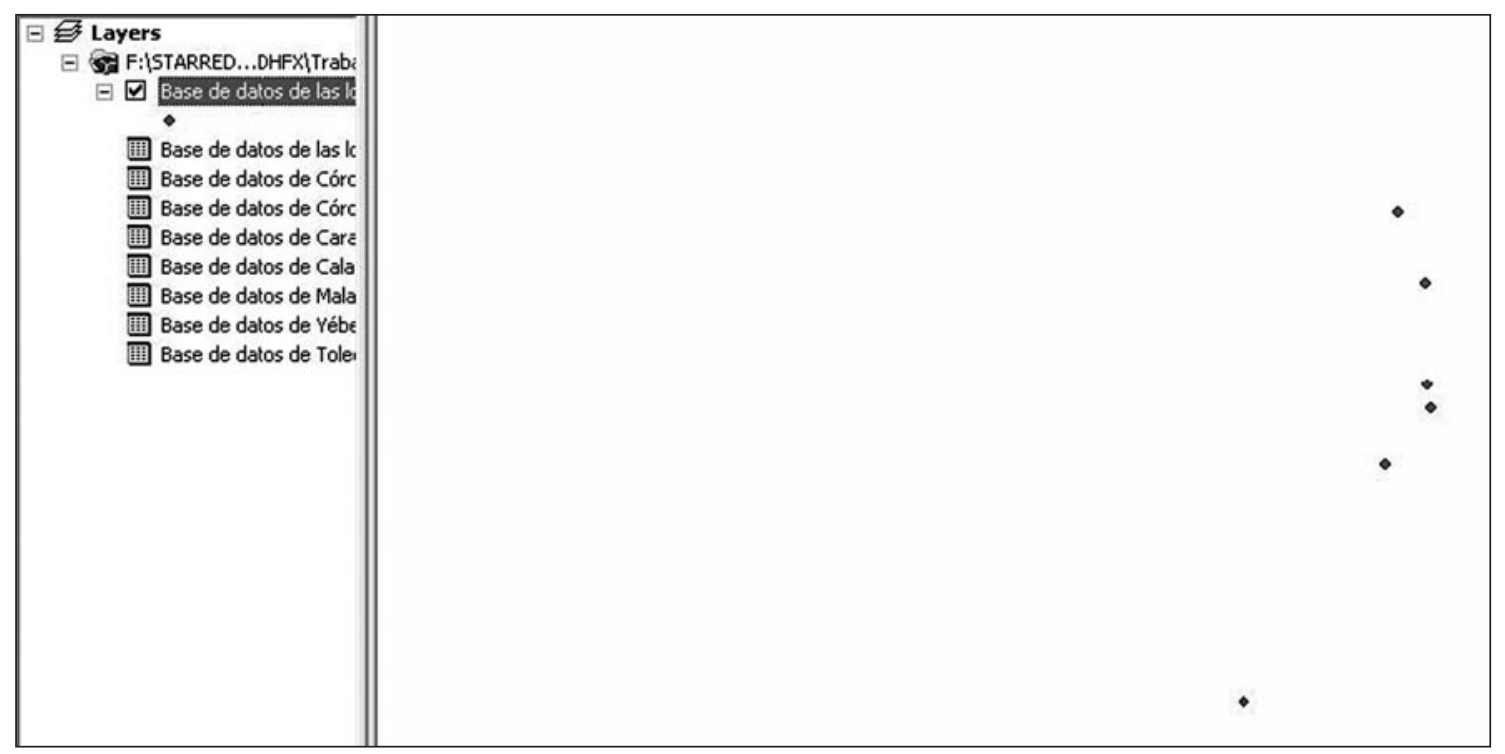

Fig. I5. Capa de puntos vectoriales que representa las localidades del trayecto entre Córdoba y Toledo, según Ibn Hawqal

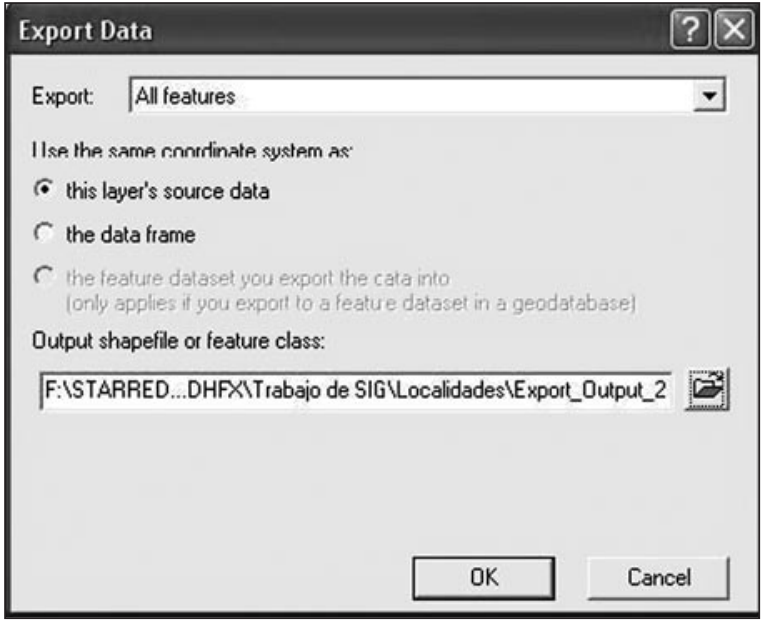

Fig. I6. Guardar la capa de puntos vectoriales haciendo click en el icono de Output shapefile or feature class

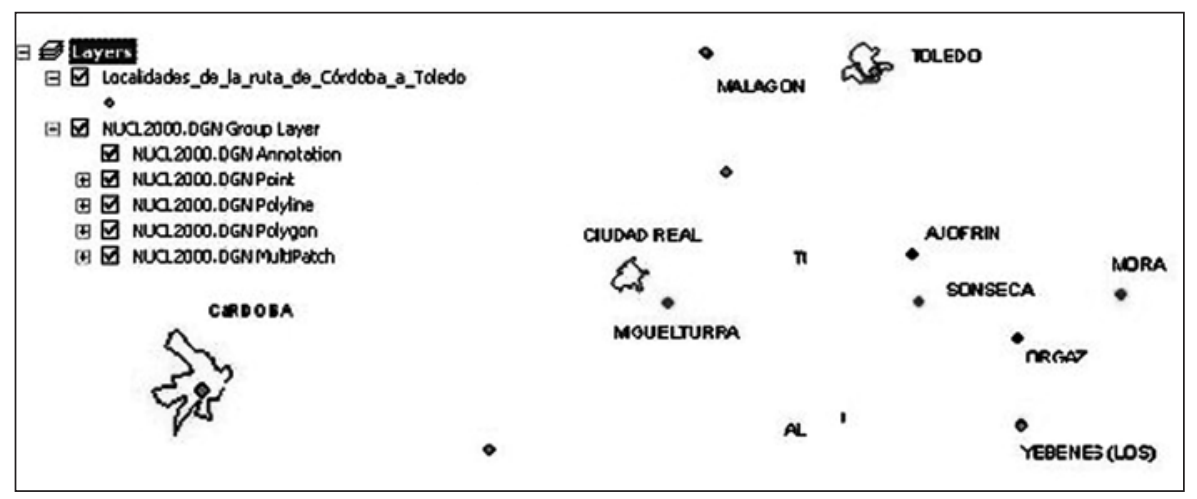

Fig. I7. Comprobación de la correcta georreferenciación de la capa de puntos vectoriales a través de su comparación con NUCL2000.DGN 


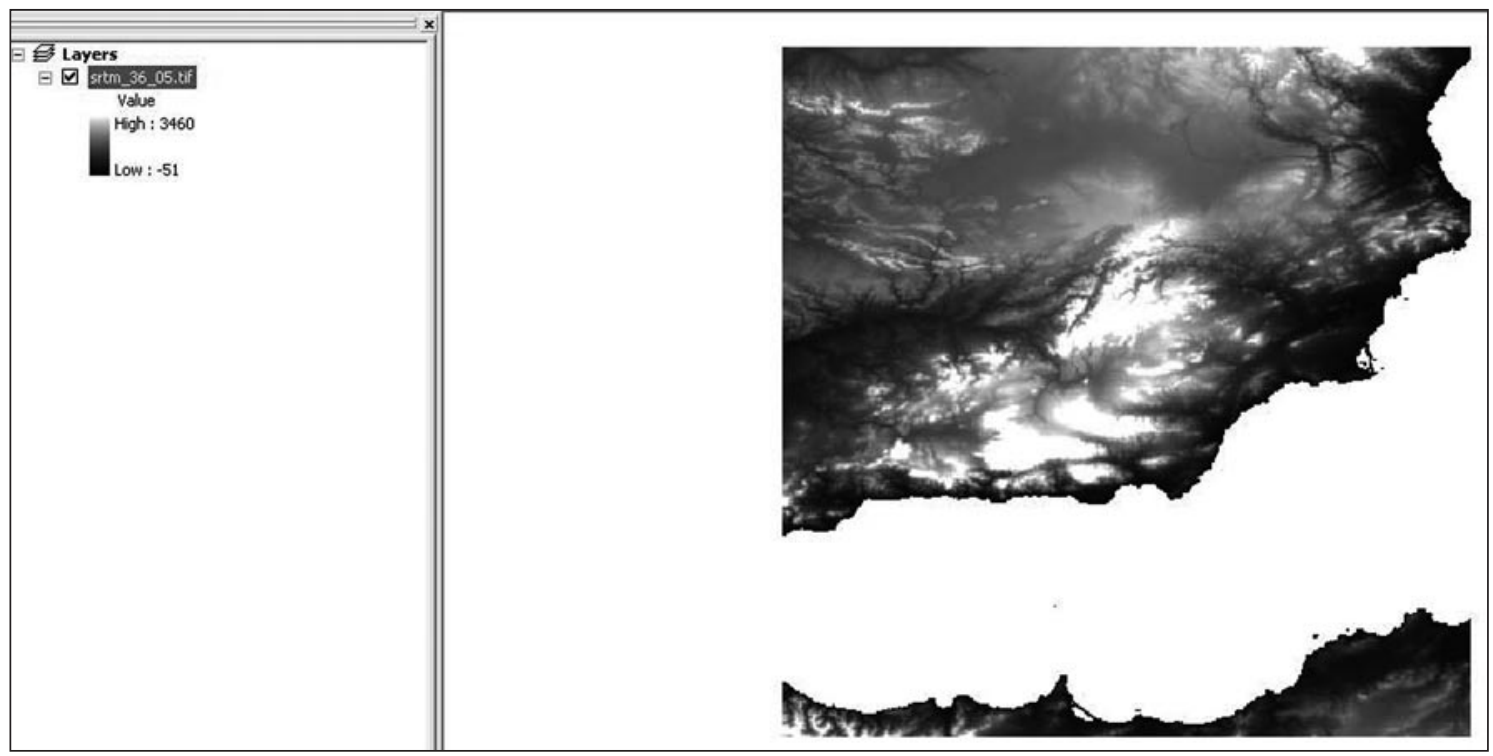

Fig. I8. MDT en formato ráster del sector Suroriental de la Península Ibérica

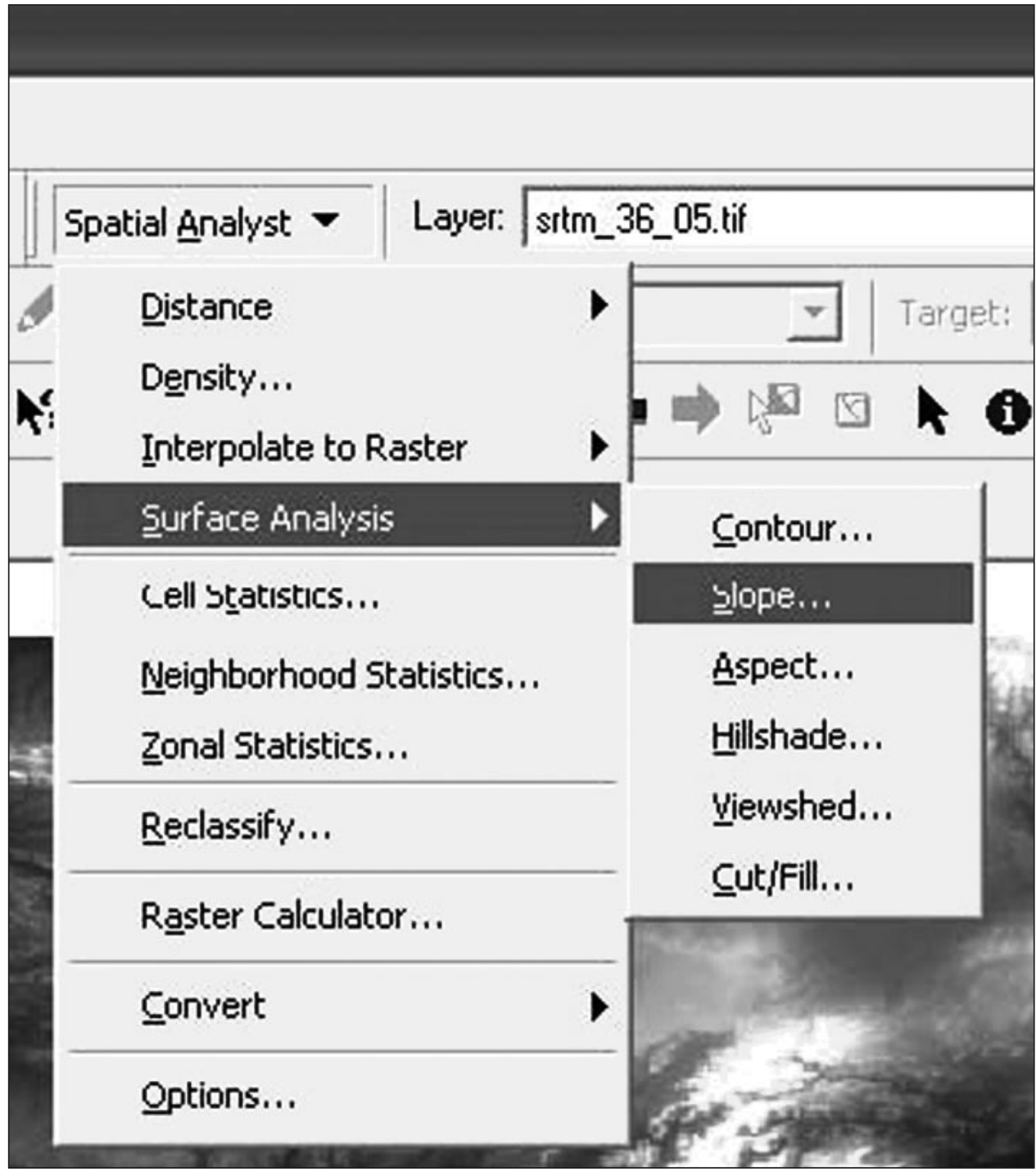

Fig. 19. Dentro del módulo Spatial Analyst, pinchar en Surface Analysis/Slope 


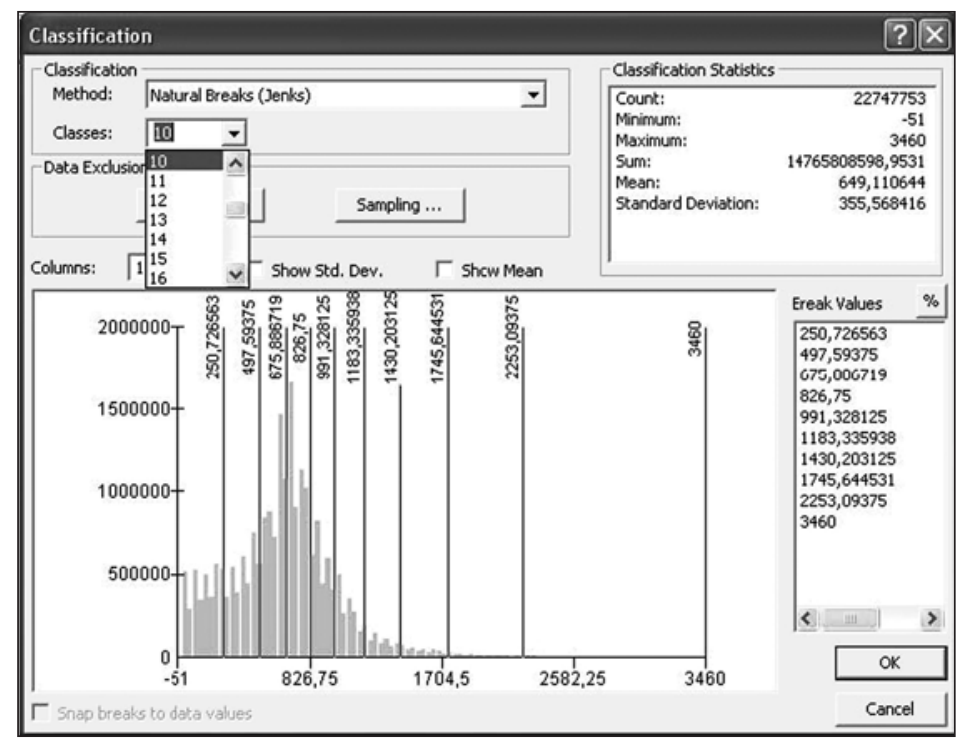

Fig. 20. Reclasificación de la pendiente en una escala de valores del 1 al 10

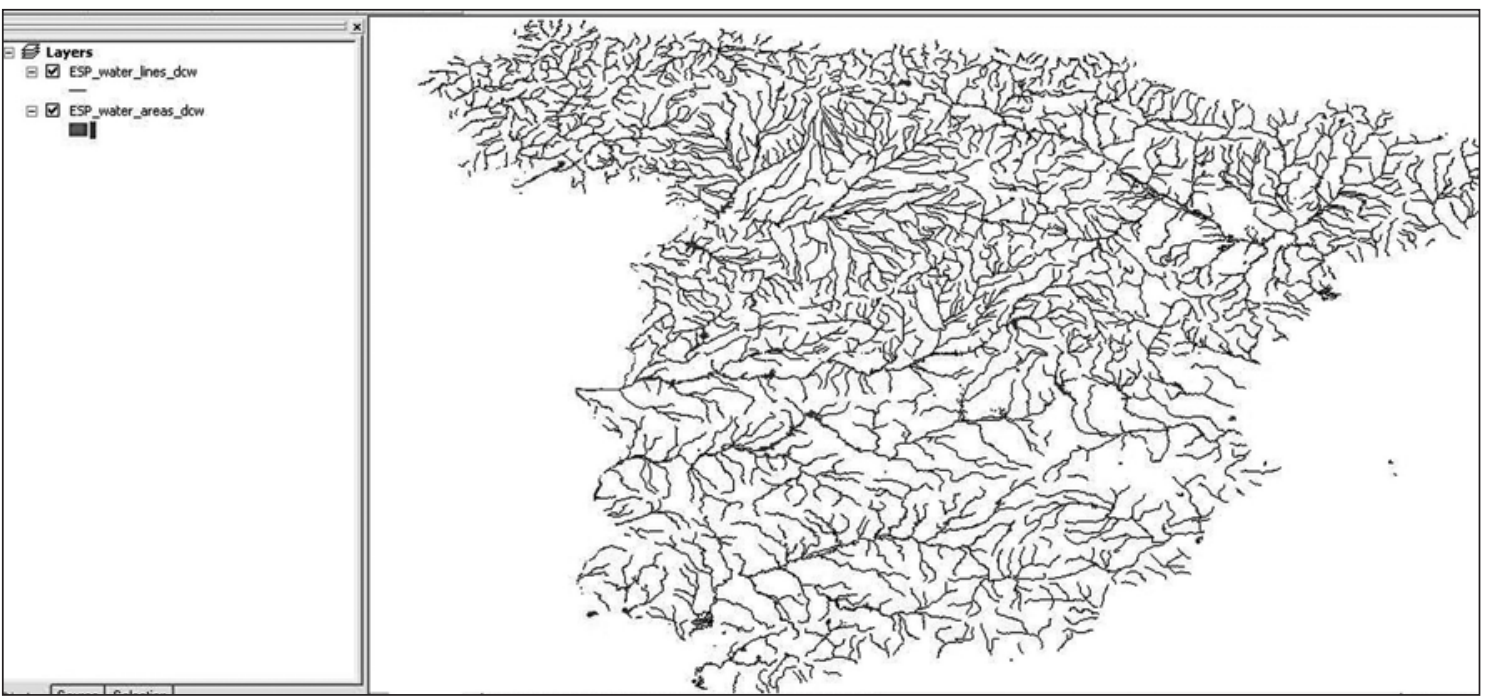

Fig. 2 I. Capas vectoriales que representan a la red hidrográfica española

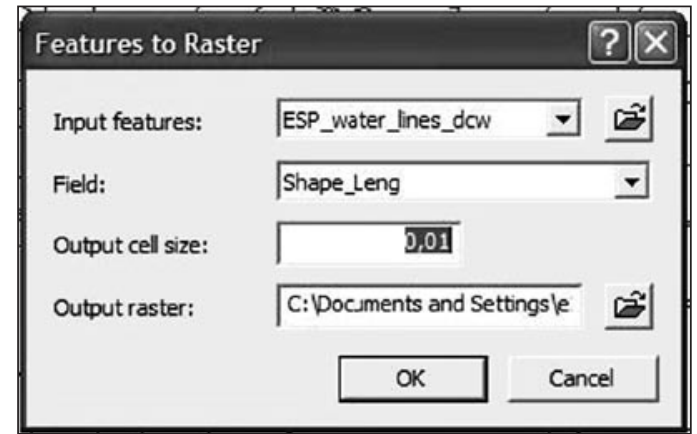

Fig. 22. Reducción de las dimensiones de las celdas hasta 0,01 y transformación de NoData en 0

Fig. 23. Uso de una escala de valores del 1 al 10 


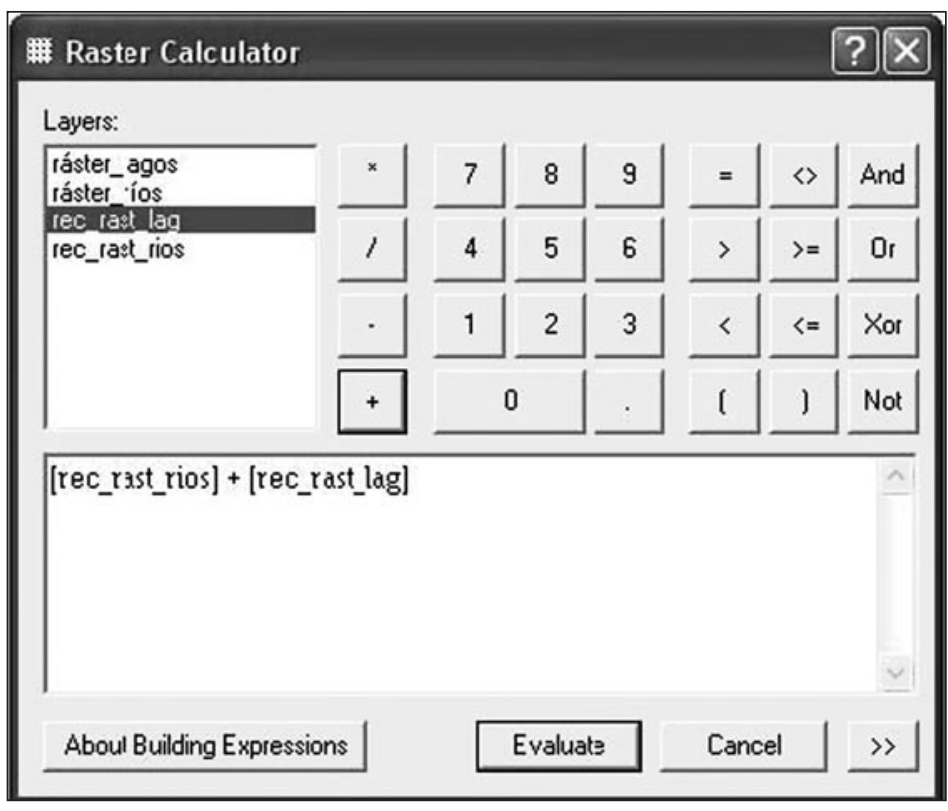

Fig. 24. Suma de las capas rec_rast_rios y rec_rast_lag

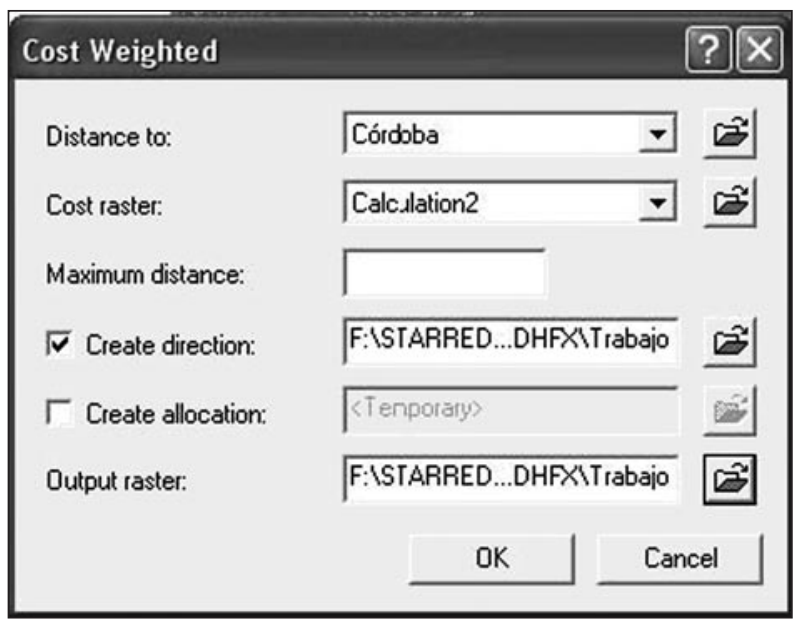

\begin{tabular}{lll|}
\hline Shortest Path & \\
Path to: & Toledo \\
Cost distance raster: & Costdístancia \\
Cost direction raster: & Cosidireccion \\
Path type: & For Each Cell \\
Output features: & F:ISTARRED...DHFXITrabajo \\
& & OK \\
& & \\
& &
\end{tabular}

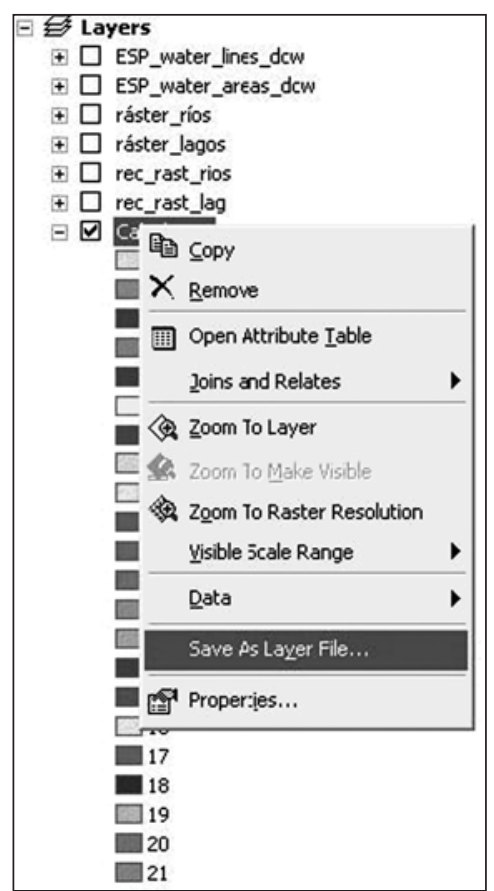

Fig. 25. Guardar la nueva capa pinchando con el botón derecho del ratón sobre ella y haciendo click en Save As Layer File...

Fig. 26. Creación de las capas ráster de coste de distancia desde Córdoba y de dirección
Fig. 28. Polilínea vectorial que representa el camino de menor coste entre Córdoba y Toledo

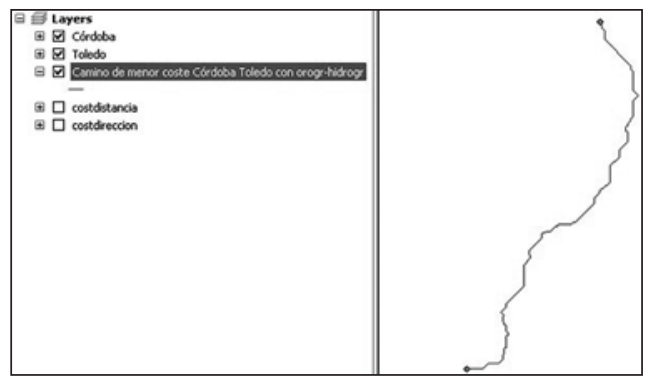




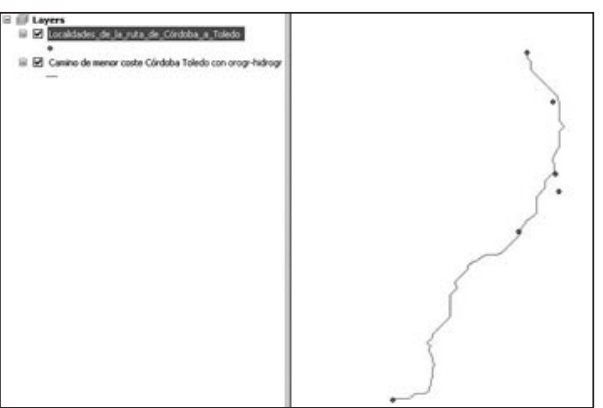

Fig. 29. Comparación del camino de menor coste entre Córdoba y Toledo con las localidades que Ibn Hawqal propuso para el trayecto entre las dos ciudades

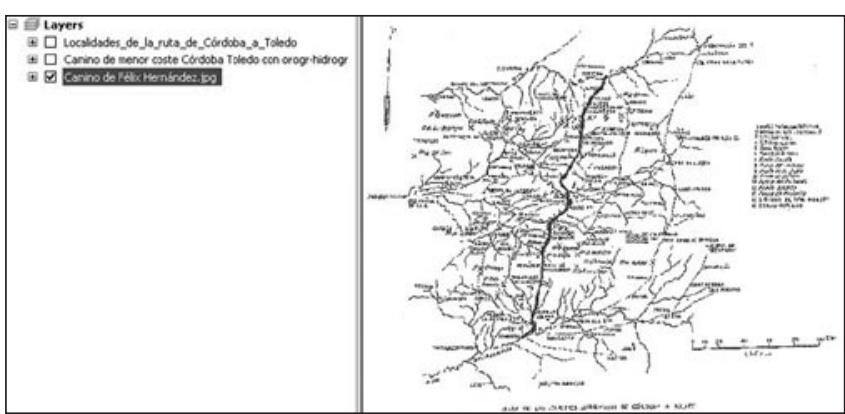

Fig. 30. Capa ráster que contiene el mapa de Félix Hernández con su propuesta sobre la vía califal entre Córdoba y Toledo (el resalte del camino es nuestro)

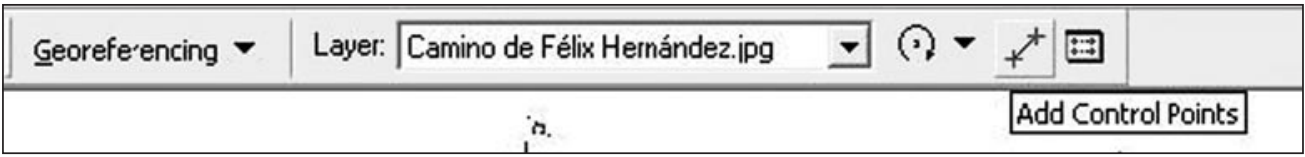

Fig. 3I. En el módulo Georeferencing pulsar sobre Add Control Points

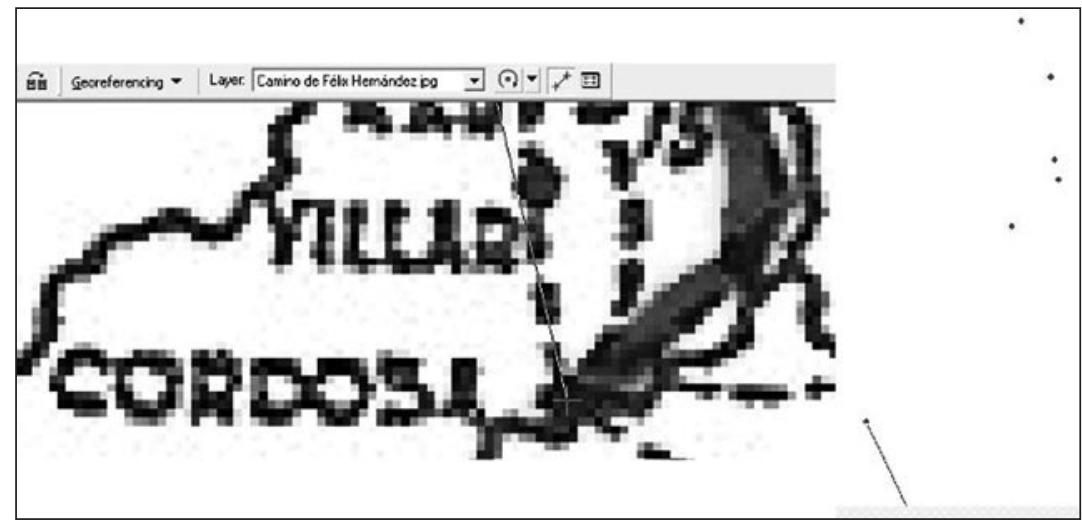

Fig. 32. Unión del emplazamiento de Córdoba presente en el mapa con el punto vectorial georreferenciado

Fig. 33. Comparación del camino de menor coste entre Córdoba y Toledo con el trazado propuesto por Félix Hernández

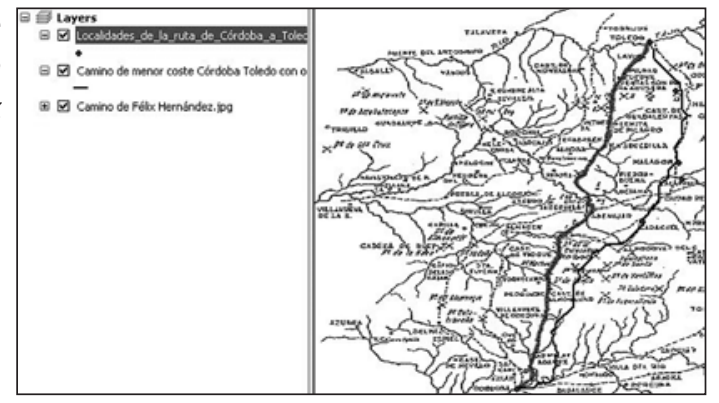

Fig. 34. Polilíneas vectoriales que representan el camino de menor coste entre Córdoba y Toledo si se toman en consideración las localidades que Ibn Hawqal menciona en el trayecto

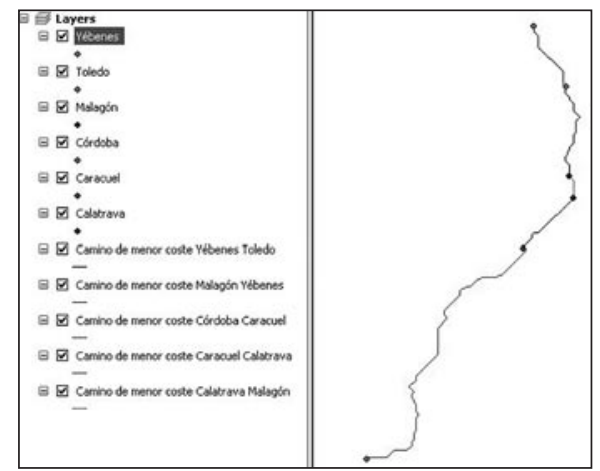

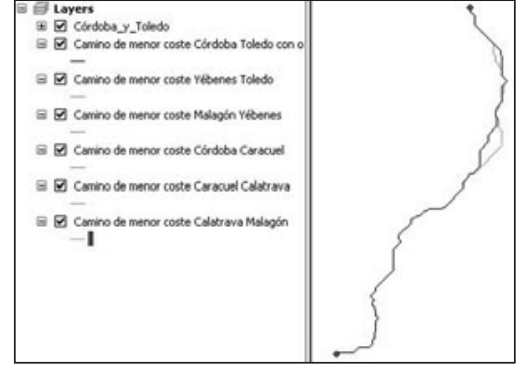

Fig. 35. Comparación del camino de menor coste entre Córdoba y Toledo con aquella que incorpora la información de Ibn Hawqal 


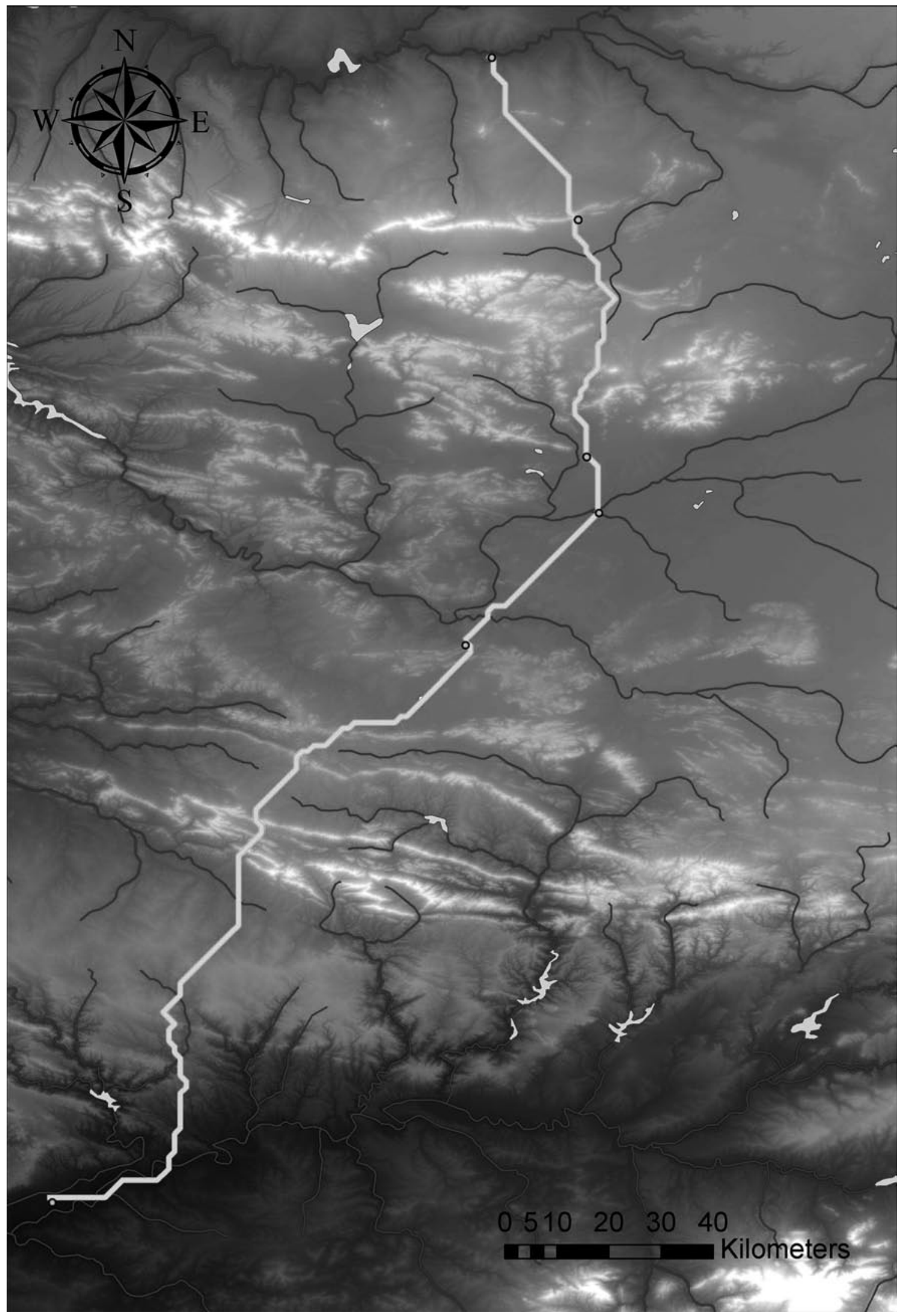

Fig. 36. Vía califal entre Córdoba y Toledo representada sobre el MDT y la red hidrográfica 